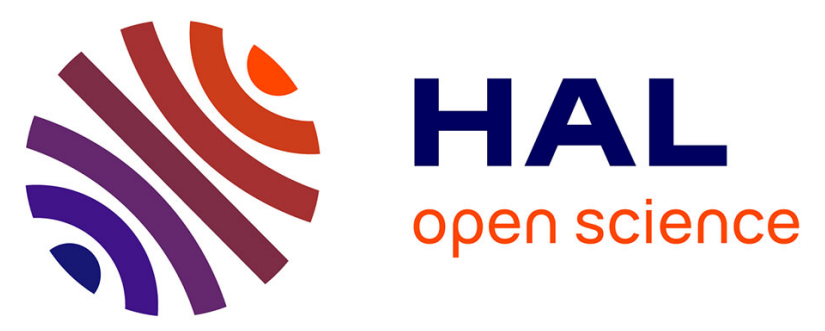

\title{
Synthesis, X-ray single crystal structure, likelihood of occurrence of intermolecular contacts, spectroscopic investigation and DFT quantum chemical calculations of zwitterionic complex: 1-Ethylpiperaziniumtrichlorozincate (II)
}

S. Soudani, E. Jeanneau, Christian Jelsch, Fabrice Lefebvre, C. Ben Nasr

\section{To cite this version:}

S. Soudani, E. Jeanneau, Christian Jelsch, Fabrice Lefebvre, C. Ben Nasr. Synthesis, X-ray single crystal structure, likelihood of occurrence of intermolecular contacts, spectroscopic investigation and DFT quantum chemical calculations of zwitterionic complex: 1-Ethylpiperaziniumtrichlorozincate (II). Journal of Molecular Structure, 2017, 1146, pp.70-79. 10.1016/j.molstruc.2017.05.096 . hal-02365380

\author{
HAL Id: hal-02365380 \\ https://hal.science/hal-02365380
}

Submitted on 16 Feb 2022

HAL is a multi-disciplinary open access archive for the deposit and dissemination of scientific research documents, whether they are published or not. The documents may come from teaching and research institutions in France or abroad, or from public or private research centers.
L'archive ouverte pluridisciplinaire HAL, est destinée au dépôt et à la diffusion de documents scientifiques de niveau recherche, publiés ou non, émanant des établissements d'enseignement et de recherche français ou étrangers, des laboratoires publics ou privés. 


\title{
Synthesis, X-ray Single Crystal Structure, likelihood of occurrence of intermolecular contacts, spectroscopic investigation and DFT quantum chemical calculations of zwitterionic complex: 1- ethylpiperaziniumtrichlorozincate (II)
}

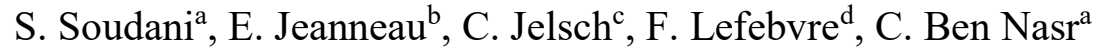

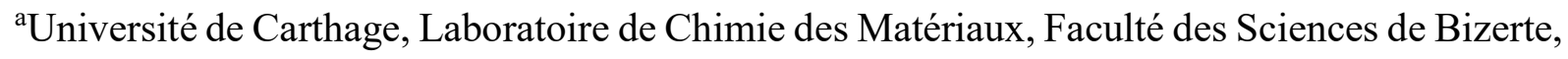 \\ 7021 Zarzouna, Tunisie, \\ ${ }^{\mathrm{b} C e n t r e}$ de Diffractométrie Henri Longchambon, Université Claude Bernard Lyon 1, \\ Villeurbanne, France, \\ ${ }^{\mathrm{c}} \mathrm{CRM}^{2}, \mathrm{CNRS}$, Institut Jean Barriol, Université de Lorraine, Vandoeuvre les Nancy CEDEX, \\ France, \\ ${ }^{\mathrm{d}}$ Laboratoire de Chimie Organométallique de Surface (LCOMS), Ecole Supérieure de Chimie \\ Physique Electronique, 69626 Villeurbanne Cedex, France.
}

Keywords: Trichlorozincate (II); Crystal structure; Hirshfeld surface; enrichment ratio; Quantum; DFT; DSC; Infrared 


\begin{abstract}
The synthesis and the X-ray structure of the $\mathrm{Zn}(\mathrm{II})$ zwitterionic complex:1ethylpiperaziniumtrichlorozincate (II) are described. In the atomic arrangement, the $\mathrm{ZnCl}_{3} \mathrm{~N}$ entities, grouped in pairs, are deployed along the $b$-axis to form layers. The organic entities are inserted between these layers through $\mathrm{N}-\mathrm{H} . . . \mathrm{Cl}$ and $\mathrm{C}-\mathrm{H}$... Cl hydrogen bonds to form infinite three-dimensional network. The 3D Hirshfeld surfaces were investigated for intermolecular interactions. The optimized geometry, Mulliken charge distribution, molecular electrostatic potential (MEP) maps and thermodynamic properties have been calculated using the Lee-YangParr correlation functional B3LYP with the LanL2DZ basis set. The HOMO and LUMO energy gap and chemical reactivity parameters were made. The ${ }^{13} \mathrm{C}$ and ${ }^{15} \mathrm{~N}$ CP-MAS NMR spectra are in agreement with the X-ray crystal structure. The vibrational absorption bands were identified by infrared spectroscopy. DFT calculations allowed the attribution of the NMR peaks and of the IR bands.
\end{abstract}

\title{
Introduction
}

Polymeric and extended metal (II) halide complexes have recently received a great attention for their particular properties related to their ability to optimize both the inorganic and organic components. These materials have recently attracted further interest due to their potentially interesting catalytic, thermal, magnetic and electrical properties. The polymeric halometallates with $\mathrm{Zn}(\mathrm{II})$ metal ion, which have been reported to exhibit a wide range of attractive properties, such as optical, photoluminescent, catalytic, and electrical properties [110], belong to this class of compounds. The $\mathrm{Zn}$ (II) metal is recognized to be essential for life, being present in several naturally occurring metalloenzymes. Then, the metal complexes should be investigated as potential cytotoxic agents. In fact, we are now interested in the synthesis, the 
Hirshfeld surface analysis and the physicochemical characterization of the 1ethylpiperaziniumtrichlorozincate (II) zwitterionic complex in the course of an ongoing program of research regarding the metal complexes of 1-ethylpiperazine. The synthesized complex, 1-ethylpiperaziniumtrichlorozincate (II), is isostructural to trichloro(1ethylpiperazin-1-ium)cobalt(II), for which only the structural study has been described [11].

\section{Experimental procedure}

\section{Chemical preparation}

A solution of 1-ethylpiperazine $(11.4 \mathrm{mg}, 0.1 \mathrm{mmol})$ dissolved in $15 \mathrm{~mL}$ of absolute ethanol and $\mathrm{ZnCl}_{2}(0.137 \mathrm{~g}, 1 \mathrm{mmol})$ dissolved in water, were mixed with an aqueous $\mathrm{HCl}$ solution $(2 \mathrm{M}, 20 \mathrm{~mL})$. The resulting solution was evaporated slowly at room temperature over a period of several days, leading to the formation of transparent colorless prismatic crystals with suitable dimensions for single crystal structural analysis. The crystals were isolated after several days and subjected to X-ray diffraction analysis. They are stable for months under normal conditions of temperature and humidity (yield 73\%). Anal. Calc.: C, $25.09 \%$; H, 5.22 \%; N, 9.75\%. Found: C, $25.14 \%$; H, $5.18 \%$; , 9.81\%.

\section{Computational details}

The theoretical calculations were performed using GaussView molecular visualization program [12] and Gaussian 09W program package [13]. he molecular structure of our compound was fully optimized using the DFT approach. The B3LYP method with $6-31+G(d, p)$ basis set was used for all atoms except for the metal LanL2DZ is used. The NMR chemical shifts and infrared spectrum were calculated with the Gaussian 09 software. All calculations were made at the B3LYP/6-311++G** level. The positions of the atoms were those determined by the X-ray diffraction study except for the hydrogen atoms which were first optimized at the same level of theory. Indeed the positions determined by X-ray do not correspond to the location 
of the proton but to that of the barycenter of charges. The chemical shifts were then calculated by use of the GIAO method. The infrared spectrum was also calculated and the absence of imaginary frequencies was checked. The same calculations were also performed after a full optimization of the complex.

$X$-ray single crystal structural analysis

A single crystal was carefully selected under polarizing microscope in order to perform its structural analysis by X-ray diffraction. Diffraction data were collected on a Gemini diffractometer with graphite-monochromatized $\operatorname{MoK} \alpha$ radiation $(\lambda=0.71073 \AA)$ and equipped with an Atlas CCD detector. Intensities were collected at $100 \mathrm{~K}$ by means of the CrysAlisPro software [14]. Reflection indexing, unit-cell parameters refinement, Lorentz-polarization correction, peak integration and background determination were carried out with the CrysAlisPro software [14]. An analytical absorption correction was applied using the modelled faces of the crystal [15]. The structure was solved by direct methods with the SIR97 suite of programs [16] and refinements were performed on $F^{2}$ by full-matrix least-squares methods with all non-hydrogen atoms anisotropic. The $\mathrm{H}$ atoms were all located in a difference map, but those attached to carbon atoms were repositioned geometrically. The $\mathrm{H}$ atoms were initially refined with soft restraints on the bond lengths and angles to regularize their geometry $(\mathrm{C}-\mathrm{H}$ in the range $0.93-0.98, \mathrm{~N}-\mathrm{H}$ in the range $0.86-0.89, \mathrm{~N}-\mathrm{H}$ to $0.86, \mathrm{O}-\mathrm{H}=0.82 \AA$ ) and $U_{\text {iso }}(\mathrm{H})$ (in the range 1.2-1.5 times $U_{\text {eq }}$ of the parent atom), after which the positions were refined with riding constraints. The structure was refined by CRYSTALS [17]. The crystal data are gathered in Table 1. The drawings were made with Diamond [18] and Mercury [19].

\section{NMR and IR measurements}

The NMR spectra were recorded on a solid-state high-resolution Bruker DSX-300 spectrometer operating at $75.49 \mathrm{MHz}$ for ${ }^{13} \mathrm{C}$ and $30.30 \mathrm{MHz}$ for ${ }^{15} \mathrm{~N}$ with a classical $4 \mathrm{~mm}$ probehead allowing spinning rates up to $10 \mathrm{kHz} \cdot{ }^{13} \mathrm{C}$ and ${ }^{15} \mathrm{~N}$ NMR chemical shifts are given 
relative to tetramethylsilane and neat nitromethane, respectively (precision $0.5 \mathrm{ppm}$ ). The spectra were recorded by use of cross polarization (CP) from protons (contact time $2 \mathrm{~ms}$ ) and magic angle spinning (MAS). Before recording the spectrum it was checked that there was a sufficient delay between the scans allowing a full relaxation of the protons. The IR spectra were recorded in the range $4000-400 \mathrm{~cm}^{-1}$ with a "Perkin-Elmer FTIR"' spectrophotometer1000 using samples dispersed in spectroscopically pure $\mathrm{KBr}$ pressed into a pellet.

\section{Results and discussion}

$X$-ray diffraction study

The asymmetric unit of the title compound contains one protonated 1ethyl)piperazinium cation coordinating a zinc atom, that is further terminally bound by three chlorine atomsas shown in Fig. 1. This compound is a so called "zwitterion" where the 1ethyl)piperazine ligand has one positive charge that is derived from the protonated nitrogen atom while the negative charge is found in the vicinity of the three chlorine atoms. The $\mathrm{Zn}$ atom has a slightly distorted tetrahedral geometry, coordinating with a nitrogen atom from one 1ethyl)piperazinium ligand and three terminal chlorine atoms. This complex is isostructural to trichloro(1-ethylpiperazin-1-ium)cobalt(II) [11]. In particular they are zwitterionic species with the 1-ethylpiperazinium ring protonated at the N2 nitrogen atom, the piperazine ring is in the characteristic chair conformation and both complexes present a very uncommon and distorted tetrahedral amino trichloro metal(II), $\mathrm{NMCl}_{3}$ group, where $\mathrm{N}$ is a nitrogen atom of the aliphatic amine.

In the $\mathrm{ZnCl}_{3} \mathrm{~N}$ tetrahedron, the $\mathrm{Zn}-\mathrm{Cl}$ bond lengths range from 2.2306(13) to 2.2532(11) $\AA$ with an average value of $2.2425 \AA$ (Table 2), which are normal and comparable with the counterparts found in the literature [20]. The bond angles of $\mathrm{Cl}-\mathrm{Zn}-\mathrm{Cl}$ and $\mathrm{N}-\mathrm{Zn}-\mathrm{Cl}$ range from 102.91 (11) to 114.67 (5), which are close to those in a regular tetrahedron, and agree with 
those found for other similar compounds [21]. In the crystal, the $\mathrm{ZnCl}_{3} \mathrm{~N}$ tetrahedra interact with each other through two $\mathrm{N}-\mathrm{H}$...Cl hydrogen bonds. An $R_{2}^{2}(8)$ homosynthon [22] is formed through these hydrogen-bonding interactions giving rise to dimers located at $(0,0,0)$ and $(0,1 / 2$ , 1/2 ) (Fig. 2). The organic groups are inserted between these dimers through N-H...Cl and C$\mathrm{H} . . \mathrm{Cl}$ hydrogen bonds to form layers parallel to the (b, a+c) plane (Figs. 3 and 4, Table 3). These layers are interconnected via $\mathrm{C}-\mathrm{H}$... $\mathrm{Cl}$ hydrogen bonds to build a three-dimensional network (Fig. 3).

The conformation of the piperazine six-membered ring can be described in terms of Cremer \& Pople puckering coordinates [23], i.e. evaluating the parameters $Q$ (total puckering amplitude), $q_{2}, q_{3}, \theta$ and $\varphi$. Their calculated value for the $\mathrm{C} 1-\mathrm{C} 2-\mathrm{N} 2-\mathrm{C} 3-\mathrm{C} 4-\mathrm{N} 1$ ring are $Q=$ $0.5687 \AA, q_{2}=0.0170 \AA, q_{3}=-0.568 \AA, \theta=178.29^{\circ}$ and $\varphi=134.41^{\circ}$ corresponding to the most stable chair conformation.

\section{Hirshfeld surface and enrichment ratios of contacts}

Many applications in the recent past years demonstrated that Hirshfeld surface analysis can be very valuable in the exploration of the packing modes and intermolecular contacts. Then, molecule crystal packings are often dominated by the hydrogen bonding patterns. Visualization and exploration of intermolecular close contacts of a structure is invaluable, and this can be achieved using the Hirshfeld surface. A large range of properties can be visualized on the Hirshfeld surface with program CrystalExplorer [24] including the distance of atoms external, $d_{e}$, and internal, $d_{i}$, to the surface. The intermolecular distance information on the surface can be condensed into a two-dimensional histogram of $d_{\mathrm{e}}$ and $d_{\mathrm{i}}$, which is a unique identifier for molecules in a crystal structure, called a fingerprint plot.

Contact distances are normalized in CrystalExplorer using the van der Waals radius of the appropriate internal and external atom of the surface: 


$$
d_{\text {norm }}=\left(d_{\mathrm{i}}-\mathrm{r}_{\mathrm{i}}^{\mathrm{vdw}}\right) / \mathrm{r}_{\mathrm{i}}^{\mathrm{vdw}}+\left(d_{\mathrm{e}}-r_{\mathrm{e}}^{\mathrm{vdw}}\right) / r_{\mathrm{e}}^{\mathrm{vdw}}
$$

Analysis of intermolecular interactions using the Hirshfeld surface-based tools represents a major advance in enabling supramolecular chemists and crystal engineers to gain insight into crystal packing behavior. The percentage $C_{\mathrm{XY}}$ of actual contacts on the Hirshfeld surface between two chemical elements $\mathrm{X}, \mathrm{Y}$ in a crystal packing is information retrieved by the program CrystalExplorer.

The Hirshfeld surface in the complex $\mathrm{C}_{6} \mathrm{H}_{15} \mathrm{~N}_{2} \mathrm{ZnCl}_{3}$ is representative of the region in space where molecules come into contact. Therefore, its analysis gives the possibility of obtaining quantitative insights into the nature of intermolecular interactions in the crystalline state. The Hirshfeld surface was computed for the complex $\mathrm{C}_{6} \mathrm{H}_{15} \mathrm{~N}_{2} \mathrm{ZnCl}_{3}$ with CrystalExplorer. The visualization of the Hirshfeld three-dimensional $d_{\text {norm }}$ surface [24] of the title compound is shown in Fig. 5. The intensive red hot spots on the surface colored according to $d_{\text {norm }}$ correspond to four interactions involving the chlorine atom, which correspond to the C6-H6C...Cl2 ${ }^{\mathrm{i}}$, N2-H2N...Cl1 ${ }^{\mathrm{ii}}, \mathrm{C} 2-\mathrm{H} 2 \mathrm{~A} \ldots \mathrm{Cl} 2^{\mathrm{iii}}$ and N1-H1N...Cl3 ${ }^{\text {iv }}$ hydrogen bonds (Table 3, Fig. 6).

The definition of contacts enrichment ratios was previously described $[25,26]$. Hence, the ratio of random contacts $R_{\mathrm{XY}}$ between two chemical elements $\mathrm{X}$ and $\mathrm{Y}$ is introduced. The $R_{\mathrm{XY}}$ values are defined as if all contact types $\mathrm{X} \cdots \mathrm{Y}$ in the crystal packing were equi-distributed between all chemical types and are obtained by probability products. Then, the enrichment ratio $E_{\mathrm{XY}}$ for a pair of elements $(\mathrm{X}, \mathrm{Y})$ is defined as the ratio between the proportion of actual contacts in the crystal and the theoretical proportion of equi-distributed random contacts:

$$
E_{\mathrm{XY}}=C_{\mathrm{XY}} / R_{\mathrm{XY}}
$$

An enrichment ratio larger than unity reveals that a pair of elements has a high propensity to form contacts in crystals, while pairs which tend to avoid contacts with each other should yield an $E$ value lower than unity. 
The nature of the contacts was analyzed on the Hirshfeld surfaces of a cation and $\mathrm{ZnCl}_{3}$ moiety, not interacting with each other in the crystal, in order to obtain two full surfaces. The lowly charge Hc and more positively charged Hn hydrogen atoms were distinguished as they have different interaction properties.

The title compound divided in the cation and $\mathrm{ZnCl}_{3}$ moieties contains $51.4 \% \mathrm{H}$ and 32.5 $\% \mathrm{Cl}$ on the Hirshfeld surface. Globally, the $\mathrm{H} . . . \mathrm{Cl}$ contacts represent as much as $62.5 \%$ of the interaction surface. There are indeed two $\mathrm{C}-\mathrm{H} \ldots \mathrm{Cl}$ and two N-H...Cl hydrogen bonds in the crystal structure (Table 3, Fig. 6, Table 4).

The $\mathrm{Hc} . . \mathrm{Cl}$ interactions constitute $53.4 \%$ which is more than half of the contact surface (Table 4) and are moderately enriched with $E=1.6, \mathrm{Hc} . . . \mathrm{Cl}$ contacts can be considered as weak hydrogen bonds, they are electrostatically slightly favorable due to the small positive charge of the relatively non-polar $\mathrm{Hc}$ atoms. The $\mathrm{Hn} \cdots \mathrm{Cl}$ contacts are electrostatically very favorable due to the partial charges with opposite signs of $\mathrm{Hn}$ and of chloride atoms. They represent only $9.1 \%$ of all contacts but turn out to be very enriched with $E=2.5$.

The Hc...Hc contacts are the second most frequent interactions due to the abundance of hydrogen on the molecular surface, but these hydrophobic contacts are slightly underrepresented with an enrichment ratio of 0.77 (Table 4). The $\mathrm{Zn} . . . \mathrm{N}$ ionic bridge is the most enriched contact $(E=13)$, it represents a major attraction in the crystal despite its small surface (3.8 of the total). The Hc...Zn contacts which represent as much as $7.7 \%$ of the surface and are slightly enriched $(E=1.1)$ are presumably a secondary effect due to the proximity with the N1 atom which coordinates the $\mathrm{Zn}^{++}$atom. The electrostatically unfavorable $\mathrm{Cl} \ldots \mathrm{Cl}$ contacts, which represent only $0.8 \%$ on the Hirshfeld surface, are extremely impoverished in the crystal $(E=0.07)$. 


\section{Optimized geometry}

The optimized geometry of the title compound which confirm the convergence to the minimum on the potential energy surface, is compared with the structural parameters obtained from the Cif file and the optimized bond lengths and bond angles obtained using the B3LYP method with LanL2DZ basis set are listed in Table 2. As seen from Fig. 7, the chair conformation of the piperazine ring is changed to boat conformation therefore some variations in the bond lengths and angles are observed. Also, others bond angles are very close to the corresponding reported values obtained by XRD such as $\mathrm{N} 2-\mathrm{C} 3-\mathrm{C} 2, \mathrm{C} 1-\mathrm{C} 4-\mathrm{N} 2, \mathrm{C} 3-$ $\mathrm{C} 2-\mathrm{N} 1, \mathrm{C} 4-\mathrm{N} 2-\mathrm{C} 5, \mathrm{C} 4-\mathrm{N} 2-\mathrm{C} 3$ and $\mathrm{C} 5-\mathrm{N} 2-\mathrm{C} 3$. In general, all the calculated parameters are in good agreement with the experimental data for the title compound and the actual change in the bond lengths of C-C and C-N would be influenced by the change of the piperazine conformation and can also be explained by the reason that the calculations related to the molecule was made isolate where the intermolecular interactions around this molecule with the neighboring molecules are absent.

\section{Mulliken population analysis}

Mulliken charge transfert of atomic orbitals [27, 28] obtained using B3LYP method with LanL2DZ basis set. The charge distribution of all atoms in the title compound is shown in Fig. 8 and represented by colors according to charge. For instance, the atomic charge distribution shows the three chlorine atoms have negative charges of $-0.46022,-0.48556$ and 0.48383 a.u respectively and the $\mathrm{Zn}$ atom of the $\mathrm{ZnCl}_{3}$ part bear positive charge $(0.59052)$. The negative charge for the $\mathrm{ZnCl} 3$ part is transferred from the $\mathrm{N} 1$ of the piperazine ring which coordinate with it. As can be seen, the four carbon atoms in the piperazine ring have negative charge in the range -0.3034 to -0.38629 . The $\mathrm{C} 6$ as figure 1 of the ethyl group bear maximum 
negative charge -0.6388 , this is due to the attachment of negatively charged atoms C5 and N2 atoms. All hydrogen atoms carry positive charge in the range 0.2044 to 0.3519 .

\section{Thermodynamic analysis}

Thermodynamic data are key in the understanding and design of chemical processes. Thermodynamic parameters of this compound which was considered to be at room temperature $(298.15 \mathrm{~K})$ and at a pressure of $1 \mathrm{~atm}$ calculated at the same level of theory. All thermodynamic calculations were done in gas phase only. Several thermodynamic properties such as zero-point vibrational energy, thermal energy, specific heat capacity $\left(C_{p}\right)$, entropy $(S)$, enthalpy and the calculated dipole moment are listed in Table 5. The thermodynamic data may be used as a reactant to take part in a new reaction would provide practical information to determine different thermodynamic energies and estimate directions of chemical reactions to put into the second law of thermodynamics [29].

\section{Molecular electrostatic potential(MEP}

The molecular electrostatic potential (MEP) is used to predict the molecular reactive behavior towards electrophilic and nucleophilic attack and defined sites of electrophile (electron-deficient positively charged species) and the nucleophile (an electron rich, negatively charged species).

The negative regions of the MEP which represent high electron density appear in red and related to the electrophilic reactivity while the positive (blue) regions related to nucleophilic reactivity. As can be seen from Fig. 9, the red region located around the $\mathrm{ZnCl3}$ part which can be considered as the electrophilic reactivity while the positive region is localized on the organic cation which will be the reactive sites for nucleophilic attack and these sites involved in intermolecular contacts [30-33]. Also, Fig.9 shows the total density, contour of total density, 
alpha density, electrostatic potential, the contour of electrostatic potential and molecular electrostatic potential.

HOMO-LUMO analysis

HOMO-LUMO orbitals were calculated from the crystal data with DFT method at the B3LYP/6-31+G* level except for zinc for which the LANL2DZ pseudopotential was used. HOMO and LUMO energy gaps indicate the chemical stability of the compounds. The highest occupied molecular orbital (HOMO) which behaves as an electron donor and the lowest occupied molecular orbital (LUMO) which behaves as an electron acceptor of the molecule are displayed in Fig 10. Clearly the HOMO is localized on the inorganic part of the crystal, while the LUMO is located on the N2 nitrogen atom, bonded to the ethyl group, of the organic cation.

The ionization potential is determined using the HOMO energy value which described the ability of electron giving. The electron affinity is defined by the value of the LUMO energy which represents the ability of electron accepting [34].

Thus, we have been determined the parameters such as electronegativity, the Chemical Hardness-Softness and electrophilicity index were calculated using the energy of HOMO and LUMO energy (Table 6) and are given as follows using Koopman's theorem :

$$
\begin{aligned}
& \mu \approx-\chi=-\frac{I+A}{2} \text { (Electronegativity) } \\
& \eta \approx \frac{1-A}{2} \text { (Chemical hardness) } \\
& \zeta=\frac{1}{2 \eta} \text { (Softness) } \\
& \psi=\frac{\mu^{2}}{2 \eta} \text { (Electrophilicity index) }
\end{aligned}
$$

where ionization potential $\mathrm{I}(\mathrm{eV}) \approx-\mathrm{E}(\mathrm{HOMO})$, electron affinity $\mathrm{A}(\mathrm{eV}) \approx-\mathrm{E}(\mathrm{LUMO})$ [35-38]. Since, the chemical hardness, large HOMO-LUMO energy gap indicates that the 
compound is "hard" and small HOMO-LUMO energy gap indicates that compound is 'Soft'. The large HOMO-LUMO gap (3.493 eV) implies a good stability and a high chemical hardness for the title compound [39].

NMR results

The ${ }^{13} \mathrm{C}$ CP-MAS NMR spectrum of $\mathrm{C}_{6} \mathrm{H}_{15} \mathrm{~N}_{2} \mathrm{ZnCl}_{3}$ is shown in Fig. 11. It exhibits six well-resolved resonances corresponding to the six crystallographically independent carbon atoms. This is in agreement with only one organic molecule being present in the asymmetric unit cell as revealed by the X-ray structure determination.

The ${ }^{15} \mathrm{~N}$ CP-MAS NMR spectrum of the title compound (Fig. 12) is also in good agreement with the X-ray structure. Indeed, it exhibits two well-defined resonances at -372.4 and -346.7 ppm corresponding to the two crystallographic independent nitrogen atoms, in agreement with only one organic molecule in the asymmetric part of the unit cell.

Density functional theory (DFT) calculations were undertaken in order to assign the NMR resonances to the different crystallographic non-equivalent carbon and nitrogen atoms of the unit cell. These calculations were made at the B3LYP/6-311++G** level. The different atoms were labeled as depicted below:

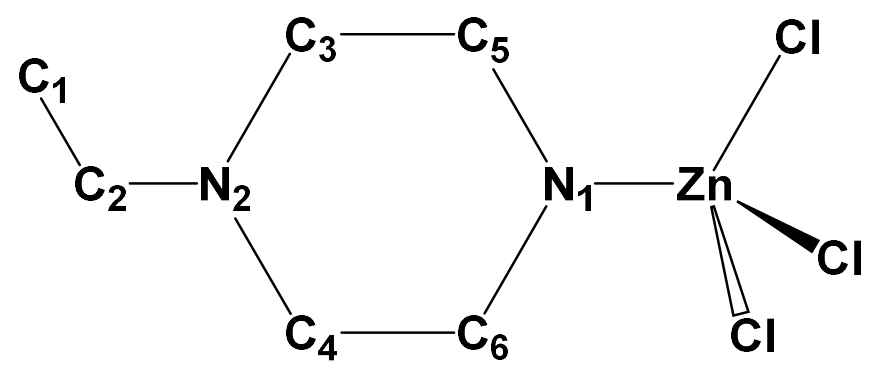


Three different calculations were made on the organic cation and in all cases the theoretical chemical shifts were subtracted from those of the reference (tetramethylsilane for carbon with $\delta_{\exp }=0 \mathrm{ppm}$ and glycine for nitrogen with $\delta_{\exp }=-347.2 \mathrm{ppm}$ ) calculated at the same level of theory:

(1) Calculation of the NMR chemical shifts (with the GIAO method) by using the positions of atoms obtained by X-ray diffraction;

(2) Optimization of the positions of the protons in the above molecule and calculation of the NMR chemical shifts in this semi-optimized geometry. Indeed X-ray diffraction leads always to underestimate $\mathrm{X}-\mathrm{H}$ bond lengths (typically below $0.1 \mathrm{~nm}$ ), due to the fact that it is sensitive to the electronic cloud and does notsee the nuclei; As a consequence the positions of protons were first optimized, the $\mathrm{C}$ and $\mathrm{N}$ atoms being located at the positions given by the $\mathrm{X}$-ray study. The resulting C-H and N-H distances correspond to what is usually obtained (typically 0.109 nm for C-H and $0.104 \mathrm{~nm}$ for $\mathrm{N}-\mathrm{H}$ ).

(3) Full optimization of all atoms and calculation of NMR chemical shifts. This calculation, compared to the above ones can give indications on the steric hindrance around the organic cation and on the positions where it is the strongest.

The results are listed on Table 7. Clearly, there is a very good agreement between the experimental and the theoretical values, particularly after optimization of all atoms, allowing unambiguously the attribution of the different NMR signals. However the optimization of all atoms leads to a modification of the configuration of the cycle to the most stable chair form. This leads to a great difference in ${ }^{15} \mathrm{~N}$ chemical shifts, those obtained after optimization of the protons only being separated by $28.7 \mathrm{ppm}$ as observed experimentally (25.7 ppm), while the full optimization leads to a difference of $20.9 \mathrm{ppm}$.

\section{4. IR spectroscopy}


To gain more information on the crystal structure, we have undertaken a vibrational study using infrared spectroscopy. The experimental IR spectrum is shown in Fig.13. The assignments of the observed bands are essentially based on comparisons with data previously reported for similar compounds [40-42].

Heterocyclic compounds containing an $\mathrm{N}-\mathrm{H}$ group exhibit $\mathrm{N}-\mathrm{H}$ stretching absorption in the region from 3500 to $3200 \mathrm{~cm}^{-1}$. In the present work, bands between 3415 and $3181 \mathrm{~cm}^{-1}$ are assigned to the stretching vibrations of the $\mathrm{N}-\mathrm{H}$ groups. The bands of medium intensities at 3011, 2967 and $2883 \mathrm{~cm}^{-1}$ were assigned to the $\mathrm{C}-\mathrm{H}$ stretching vibrations. The band observed at $2799 \mathrm{~cm}^{-1}$ was attributed to $v_{\mathrm{sym}}\left(\mathrm{NH}^{+}\right)$. The bands at 1459,1424 and $1405 \mathrm{~cm}^{-1}$ are assigned to $\mathrm{CH}_{3}$ and $\mathrm{CH}_{2}$ deformation modes. The bands of medium intensities at 1265 and $1216 \mathrm{~cm}^{-1}$ were assigned to C-N stretching. The observed bands at 1104 and $1048 \mathrm{~cm}^{-1}$ were attributed to asymmetric and symmetric $\mathrm{C}-\mathrm{C}$ stretching modes. The infrared bands observed in the range 913-500 $\mathrm{cm}^{-1}$ were assigned to $\mathrm{CCN}$ groups deformation vibrations.

The frequencies calculation was made on the geometry obtained after optimization of the positions of the protons. The resulting IR spectrum between 500 and $4000 \mathrm{~cm}^{-1}$ is shown on Fig. 14 and is very similar to the experimental one. A close agreement between the experimental and theoretical wavenumbers is mostly achieved in the fingerprint region as shown in Fig. 15. Thus, the precision is well-sufficient to assign the experimental frequencies and to confirm the attributions proposed above.

\section{Conclusion}

A new 1-ethylpiperaziniumtrichlorozincate (II) zwitterionic complex has been prepared at room temperature and characterized by physicochemical methods. On the structural level, it can be described as built up by layers of $\mathrm{ZnCl}_{3} \mathrm{~N}$ entities, which are deployed along the $b$-axis to form layers. The organic entities are inserted between these layers through N-H...Cl and C- 
$\mathrm{H} . . \mathrm{Cl}$ hydrogen bonds to form infinite three-dimensional network. The contact analysis for this compound suggests that beyond the formation of the $\mathrm{Zn}^{++} \mathrm{Cl}^{-}{ }_{3}$ complexes, the enriched $\mathrm{Zn} . . \mathrm{N}$ and $\mathrm{Hn} . . \mathrm{Cl}$ strong electrostatic interactions with the organic cation are the driving forces in molecular arrangement and crystal packing formation. The optimization geometry changed the chair conformation of the piperazine ring to boat conformation. The MEP map shows that the negative potential sites are on electronegative $\mathrm{ZnCl} 3$ part as well as the positive potential sites are around the organic cation. The HOMO-LUMO energy gap, electronegativity, electrophilicity index and chemical hardness and softness values were calculated for the title compound by means of HOMO-LUMO energy values. The thermodynamic parameters of the title compound have been determined.

The numbers of ${ }^{13} \mathrm{C}$ and ${ }^{15} \mathrm{~N}$ CP-MAS NMR lines are in full agreement with the crystallographic data. DFT calculations allow the attribution of the experimental NMR lines and of IR bands at low frequencies.

\section{Supplementary data}

Crystallographic data for the structural analysis have been deposited at the Cambridge Crystallographic Data Centre, CCDC No 1434489. These data can be obtained free of charge via http://www.ccdc.cam.ac.uk/conts/retrieving.html, or from the CCDC, 12 Union Road, Cambridge, CB2 1EZ, UK: fax: (+44) 01223-336-033; e-mail: deposit@ccdc.cam.ac.

\section{References}

[1] A. Thorn, R. D. Willett, B. Twamley, Polyhedron 25 (2006) 2891-2896.

[2] A. Kessentini, M. Belhouchet, J. J. Suñol, Y. Abid, T. Mhiri, J. Mol. Struct. 1039(2013) $207-213$ 
[3] M. Khechoubi, A. Bendani, N. B. Chanh, C. Courseille, R. Duplessix, M. Couzis, J. Phys. Chem. Solids 55 (1994) 1277-1288.

[4] L-Y. Kong, X-H. Lu, Y-Q. Huang, H. Kawaguchi, Q. Chu, H-F. Zhu, W-Y. Sun, J. Solid State Chem. 180 (2007) 331-338.

[5] F. Neve, O. Francescangeli, A. Crispini, Inorg. Chim. Acta. 338 (2002) 51-58.

[6] K. Ma, J. Xu, P. Zhang, Y. Wang, L. Wang, Y. Fan, T. Song, Solid State Sci. 8 (2006) $1473-1476$.

[7] J. Jin, M-J. Jia, Y-C. Wang, J-H. Yu, Q-F. Yang, J-Q. Xu, Inorg. Chem. Commun. 14 (2011) 1681-1684.

[8] A. B. Corradi, M. R. Cramarossa, M. Saladini, J. Giusti, A. Saccani, F. Sandrolini, Inorg. Chim. Acta 233 (1995) 85-90.

[9] H. Wang, R-G. Xiong, C-M. Liu, H-Y. Chen, X-Z. You, W. Chen, lnorg. Chim. Acta 254 (1997) 183-187.

[10] N. Karâa, B. Hamdi, A. Ben Salah, R. Zouari, J. Mol. Struct.1013 (2012) 168-176.

[11] A.C. Dhieb, D. E. Janzen, M. Rzaigui, W. Smirani, Acta Cryst. (2014) E70, m166.

[12] R. Dennington, T.Keith, J. Millam, GaussView, Version 5, Semichem Inc., Shawnee Mission KS (2009).

[13] M. J. Frisch, G. W. Trucks, H. B. Schlegel, G. E. Scuseria, M. A. Robb, J. R. Cheeseman, G. Scalmani, V. Barone, B. Mennucci, G. A. Petersson, H. Nakatsuji, M. Caricato, X. Li, H. P. Hratchian, A. F. Izmaylov, J. Bloino, G. Zheng, J. L. Sonnenberg, M. Hada, M. Ehara, K. Toyota, R. Fukuda, J. Hasegawa, M. Ishida, T. Nakajima, Y. Honda, O. Kitao, H. Nakai, T. Vreven, J. A. Montgomery, Jr., J. E. 
Peralta, F. Ogliaro, M. Bearpark, J. J. Heyd, E. Brothers, K. N. Kudin, V. N.

Staroverov, T. Keith, R. Kobayashi, J. Normand, K. Raghavachari, A. Rendell, J. C.

Burant, S. S. Iyengar, J. Tomasi, M. Cossi, N. Rega, J. M. Millam, M. Klene, J. E.

Knox, J. B. Cross, V. Bakken, C. Adamo, J. Jaramillo, R. Gomperts, R. E. Stratmann,

O. Yazyev, A. J. Austin, R. Cammi, C. Pomelli, J. W. Ochterski, R. L. Martin, K.

Morokuma, V. G. Zakrzewski, G. A. Voth, P. Salvador, J. J. Dannenberg, S. Dapprich, A. D. Daniels, O. Farkas, J. B. Foresman, J. V. Ortiz, J. Cioslowski, and D. J. Fox, Gaussian 09,Revision B.01 Gaussian, Inc., Wallingford CT, 2010.

[14] CrysAlisPro, AgilentTechnologies,Version 1.171.37.34 (release 22-05-2014 CrysAlis 171 .NET)(compiled May 22 2014,16:03:01).

[15] R. C. Clark, J. S. Reid, Acta Cryst. A51 (1995) 887-897.

[16] A. Altomare, M. C. Burla, M. Camalli, G. Cascarano, C. Giacovazzo, A. Guagliardi, A. G. Moliterni, G. Polidori, R. Spagna, J. Appl. Cryst. 32 (1999) 115-119.

[17] P. W. Betteridge, J. R. Carruthers, R. I. Cooper, K. Prout, D. J. Watkin, J. Appl. Cryst. $36(2003)$ 1487-1487.

[18] K. Brandenburg 1998 DIAMOND version 2.0.

[19] C. F. Macrae, P. R.Edgington, P. McCabe, E. Pidcock, G. P. Shields, R. Taylor, M. Towler, J. van de Streek, J. Appl. Cryst.39 (2006) 453-457.

[20] T.C.W. Mak, S.-H. Huang, Polyhedron 6 (1987) 1111-1163.

[21] W.-T.Chen, D.-S.Liu, S.-M.Ying, H.-L.Chen, Y.-P.Xu, Inorg. Chem. Commun.11 (2008) 1212-1214.

[22] J. Bernstein, R.E. Davis, L. Shimoni, N.L. Chang, Angew. Chem. Int. Ed Engl. 34, (1995) 1555-1573.

[23] D. Cremer, J. Am. Chem. Soc., 97 (1975) 1354-1358. 
[24] E. Clementi,C. Roetti, Atomic Data and Nuclear Data Tables, 14 (1974) 177-478.

[25] G. Moss, P. Coppens, Chem. Phys. Lett.75 (1980) 298-302.

[26] M. A. Spackman, P. G. Byrom, Chem. Phys. Lett. 267 (1997) 215-220.

[27] D. Arul Dhas, I. Hubert Joe, S. D. D. Roy, T. H. Freeda, Spectrochim. Acta A 177 (2010) $36-44$.

[28] R. S. Mulliken, J. Chem. Phys. 23 (1955), 1833-1840.

[29] D.A. McQuarrie, J.D. Simon, Molecular Thermodynamics, University Science Books, Sausalito, CA, 1999.

[30] A. Tokatl1, E. Özen, F. Ucun, S. Bahçeli, Spectrochim. Acta A 78 (2011) 12011211.

[31] E. Scrocco, J. Tomasi, Adv. Quant. Chem. 11 (1979) 115-121.

[32] F.J. Luque, J.M. Lopez, M. Orozco, Theor. Chem. Acc. 103 (2000) 343-345.

[33] N. Okulik, A.H. Jubert, Int. Electron J. Mol. Des. 4 (2005) 17-30.

[34] H. Saeidian, M. Sahandi, J. Mol. Struct. 1100 (2015) 486-495.

[35] H. Gökçe, S. Bahçeli, Spectrochim. Acta A 114 (2013) 61-73.

[36] W. Kohn, A.D. Becke, R.G. Parr, J. Phys. Chem. 100 (31) (1996) 12974-12980.

[37] R.G. Parr, R.G. Pearson, J. Am. Chem. Soc. 105 (26) (1983) 7512-7516.

[38] R.G. Pearson, Proc. Natl. Acad. Sci. USA 83 (22) (1986) 8440-8441.

[39] L. Xiao-Hong, L. Xiang-Ru, Z. Xian-Zhou, Spectrochim. Acta Part A 78 (2011) $528-536$.

[40] M. Silverstein, G. Clayton Basseler, C. Morill Spectrometric identification of organic compound. Wiley, New York (1981).

[41] Z. Aloui, V. Ferretti, S. Abid, M. Rzaigui, F. Lefebvre, C. Ben Nasr, J. Mol. Struct. 1087 (2015) 26-32.

[42] S. K. Seth, S. Banerjee, T. Kar, J. Mol. Struct. 965 (2010) 45-49. 


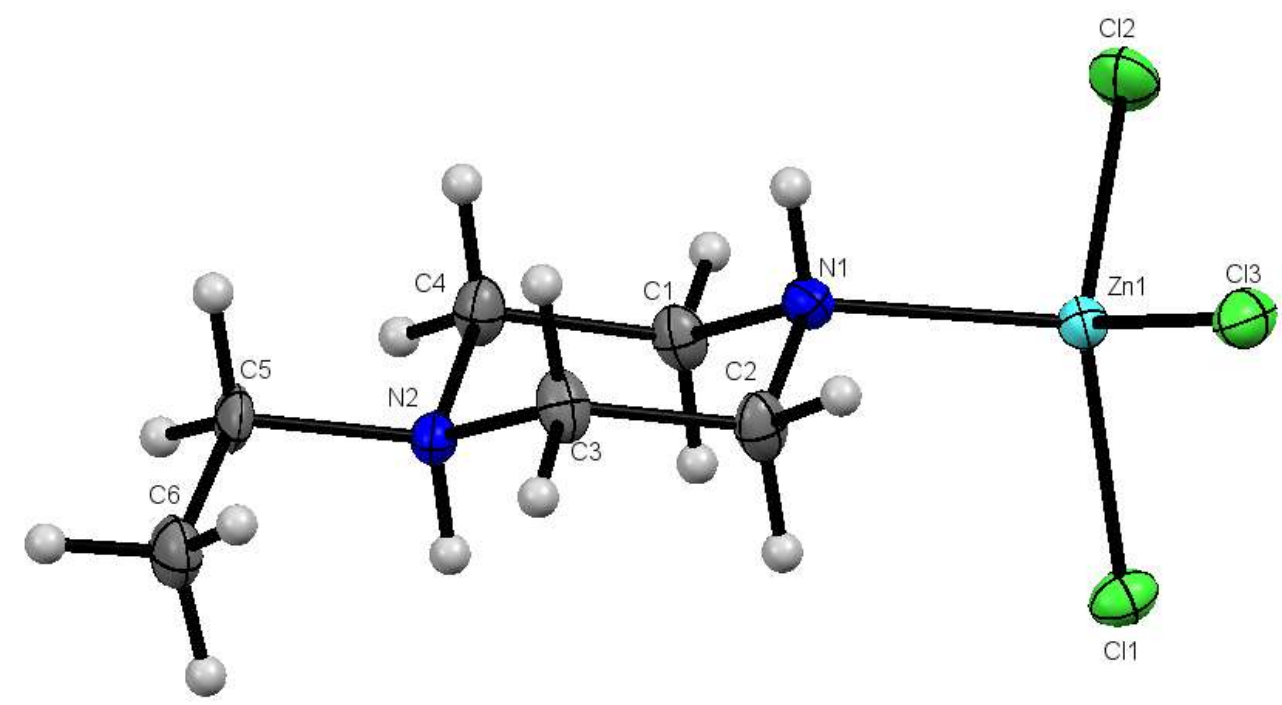

Fig. 1 A view of the asymmetric unit in the crystal structure of the title compound showing the atom-numbering scheme and displacement ellipsoids drawn at the 50\% probability level.

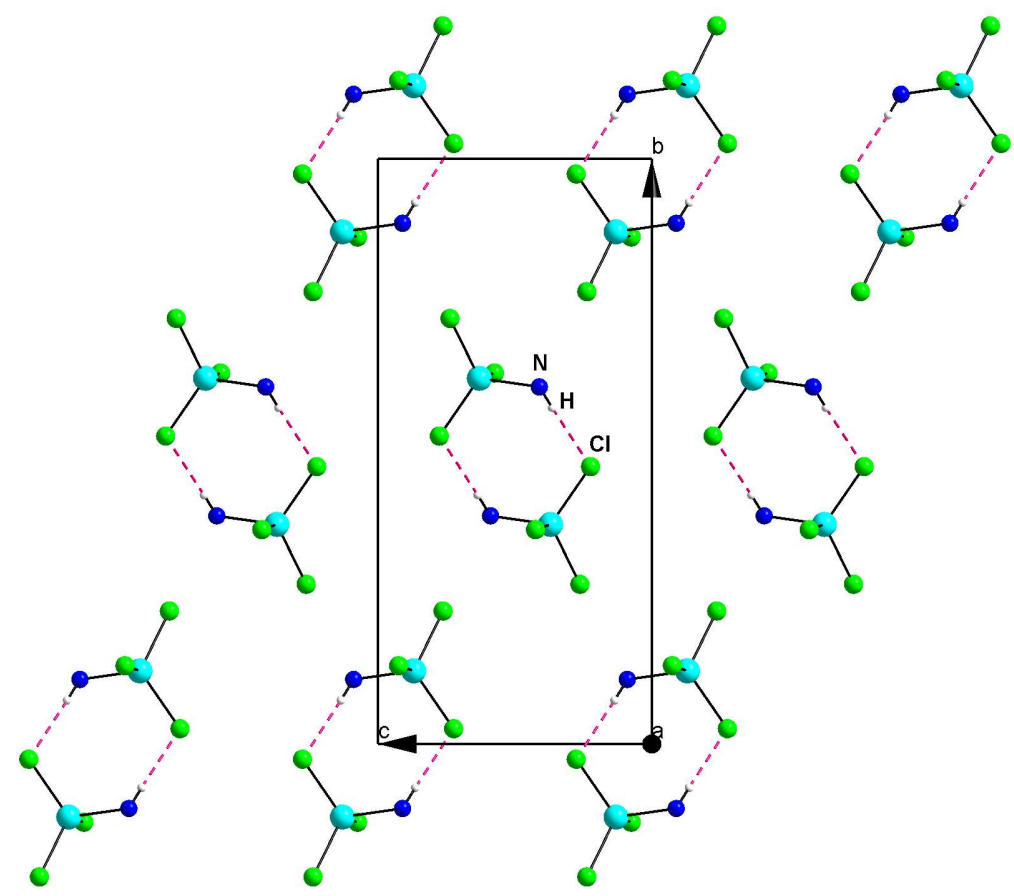

Fig. 2 Projection of dimers formed by $\mathrm{ZnCl}_{3} \mathrm{~N}$ tetrahedra in the title compound. 


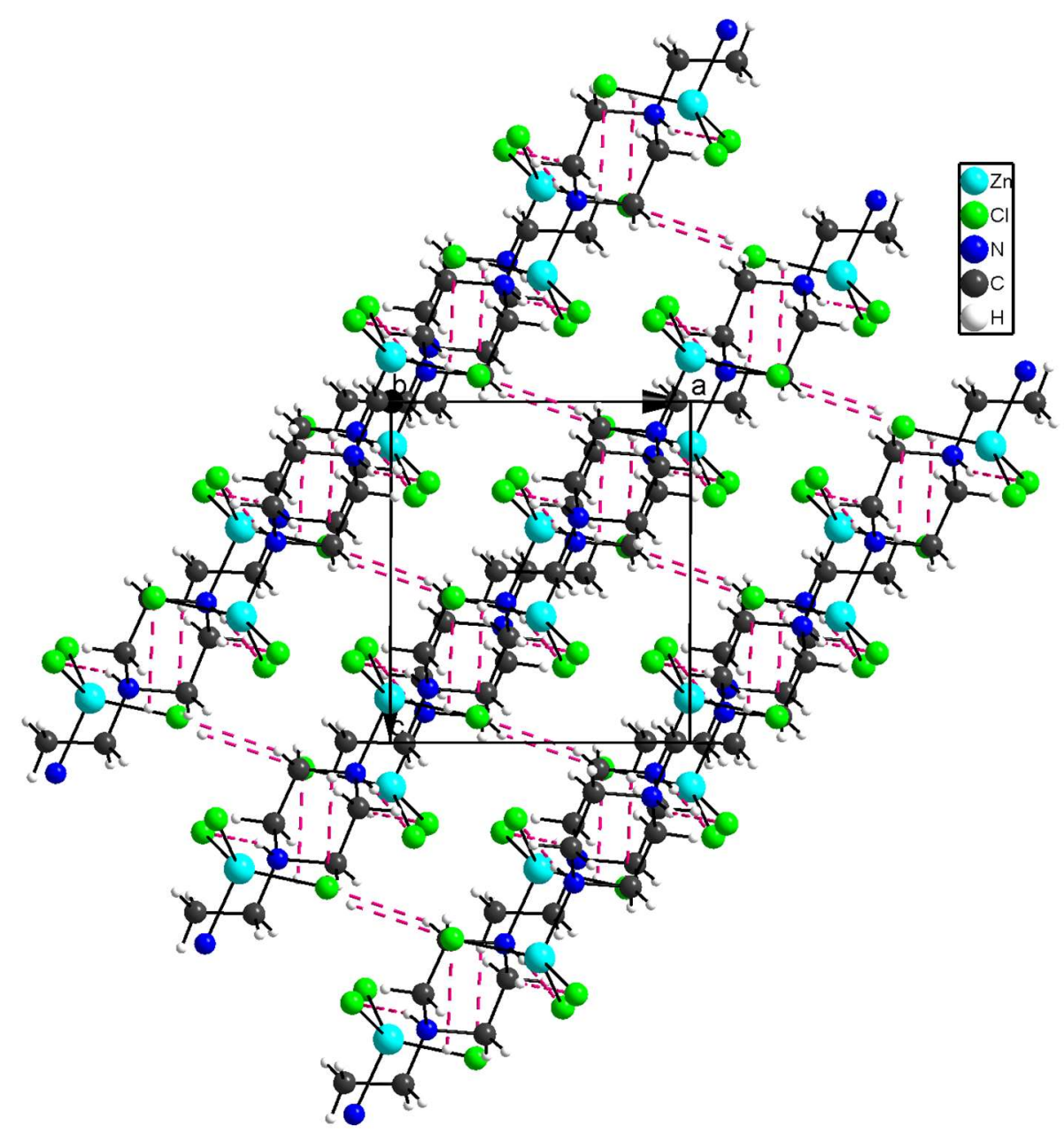

Fig. 3 Projection along the $b$-axis of the crystal packing of the title compound. The dotted lines indicate hydrogen bonds. 


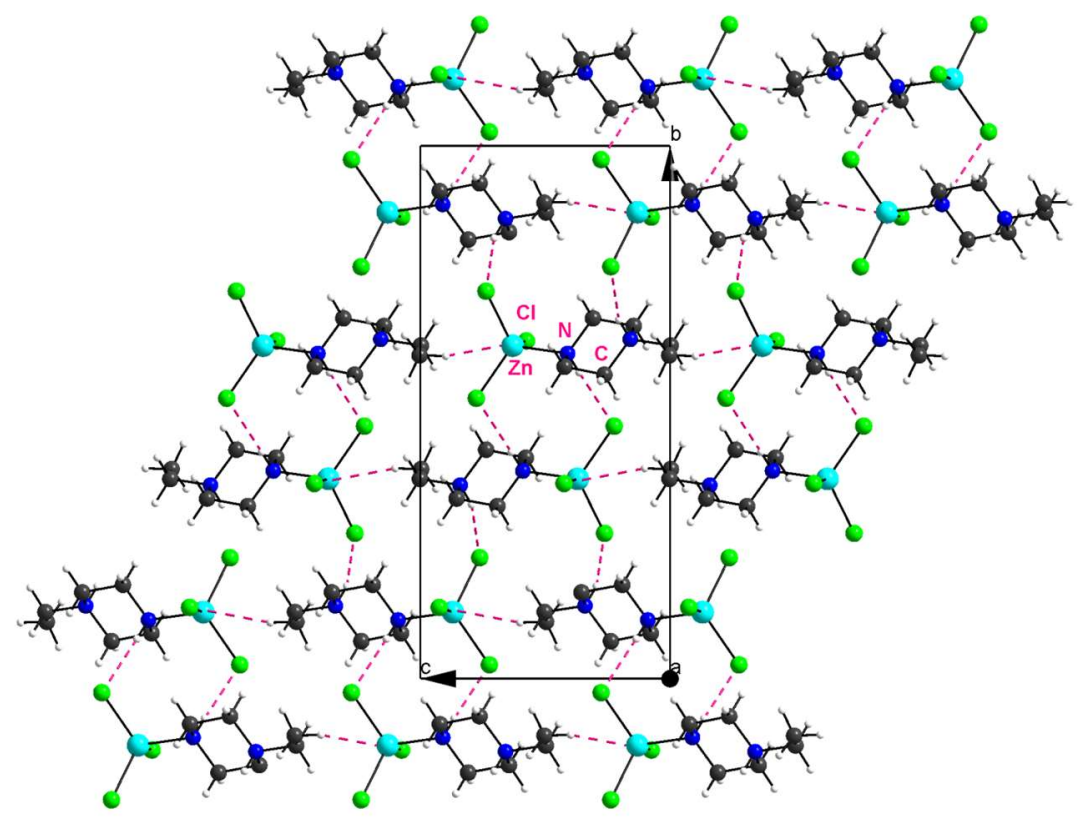

Fig. 4 View along the $a$-axis direction of an inorganic layer in the title compound.
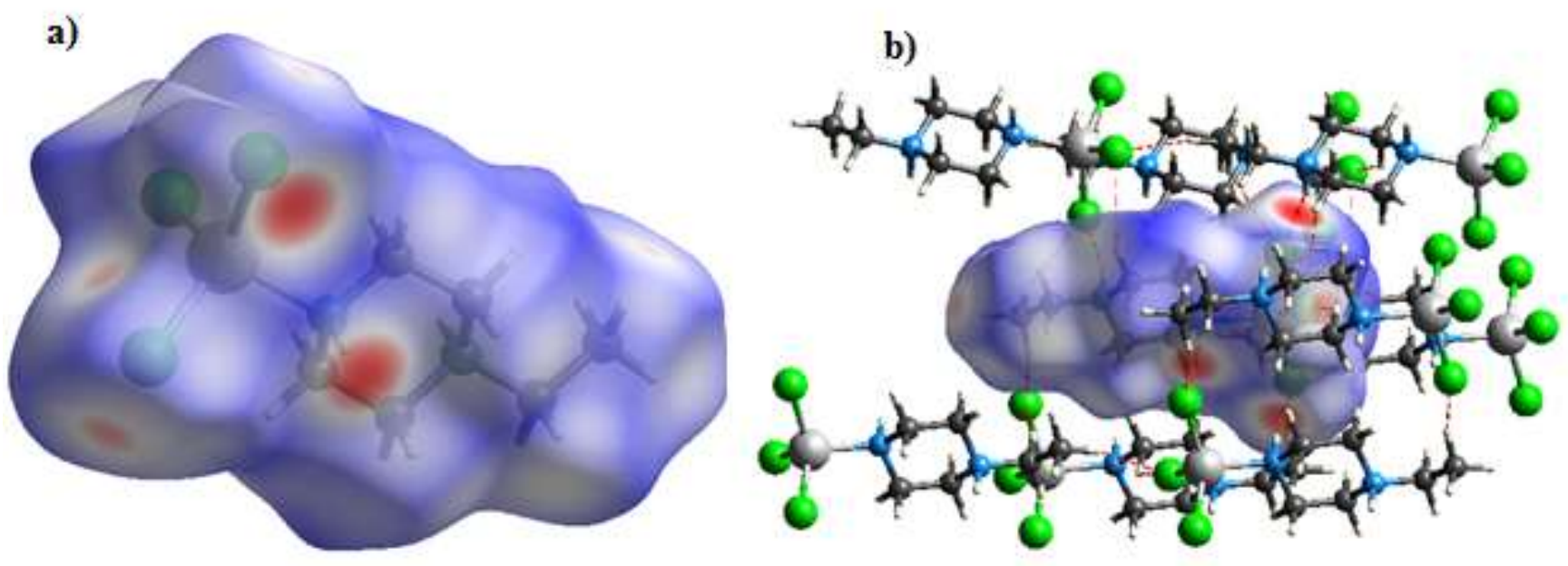

Fig. 5 View of the $d_{\text {norm }}$ quantity mapped on the Hirshfeld surface of the asymmetric unit. The red color represents the area on the surface where the atoms make intermolecular contacts closer than the sum of their van derWaals radii. 


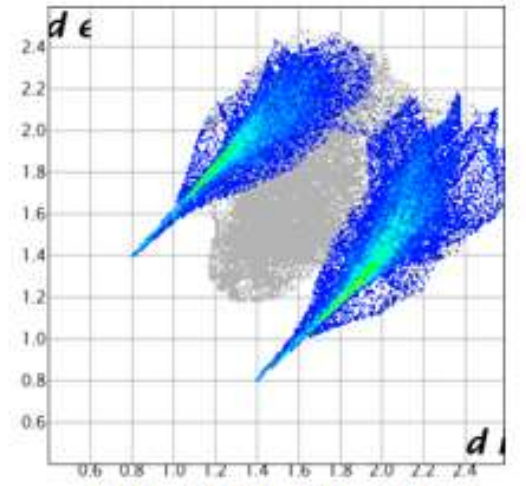

a) $\mathrm{H} . . . \mathrm{Cl} / \mathrm{Cl} . . \mathrm{H}: 63.5 \%$

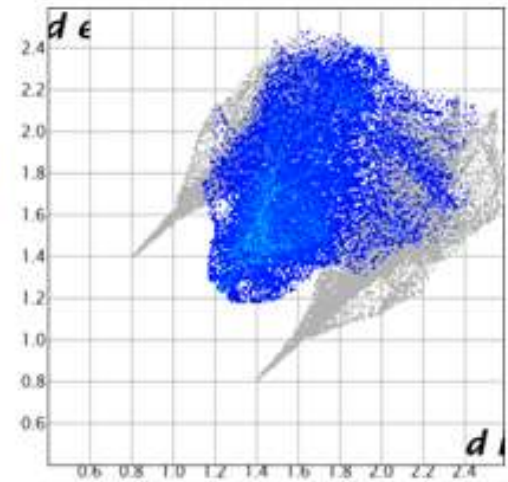

b) H...H : $34.5 \%$

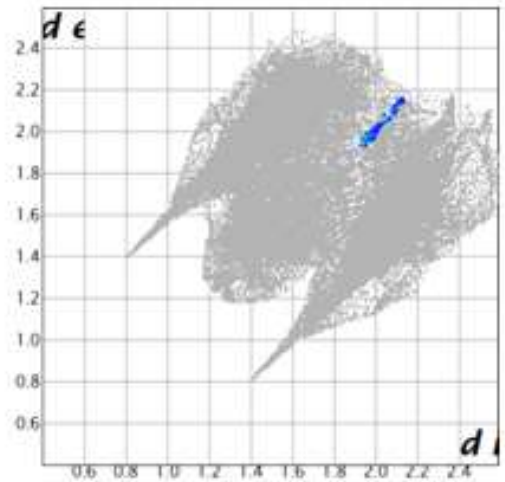

c) $\mathrm{Cl} . . \mathrm{Cl}: 0.8 \%$

Fig. 6 Fingerprint plots of the major contacts of $\mathrm{C}_{6} \mathrm{H}_{15} \mathrm{~N}_{2} \mathrm{ZnCl}_{3}$.

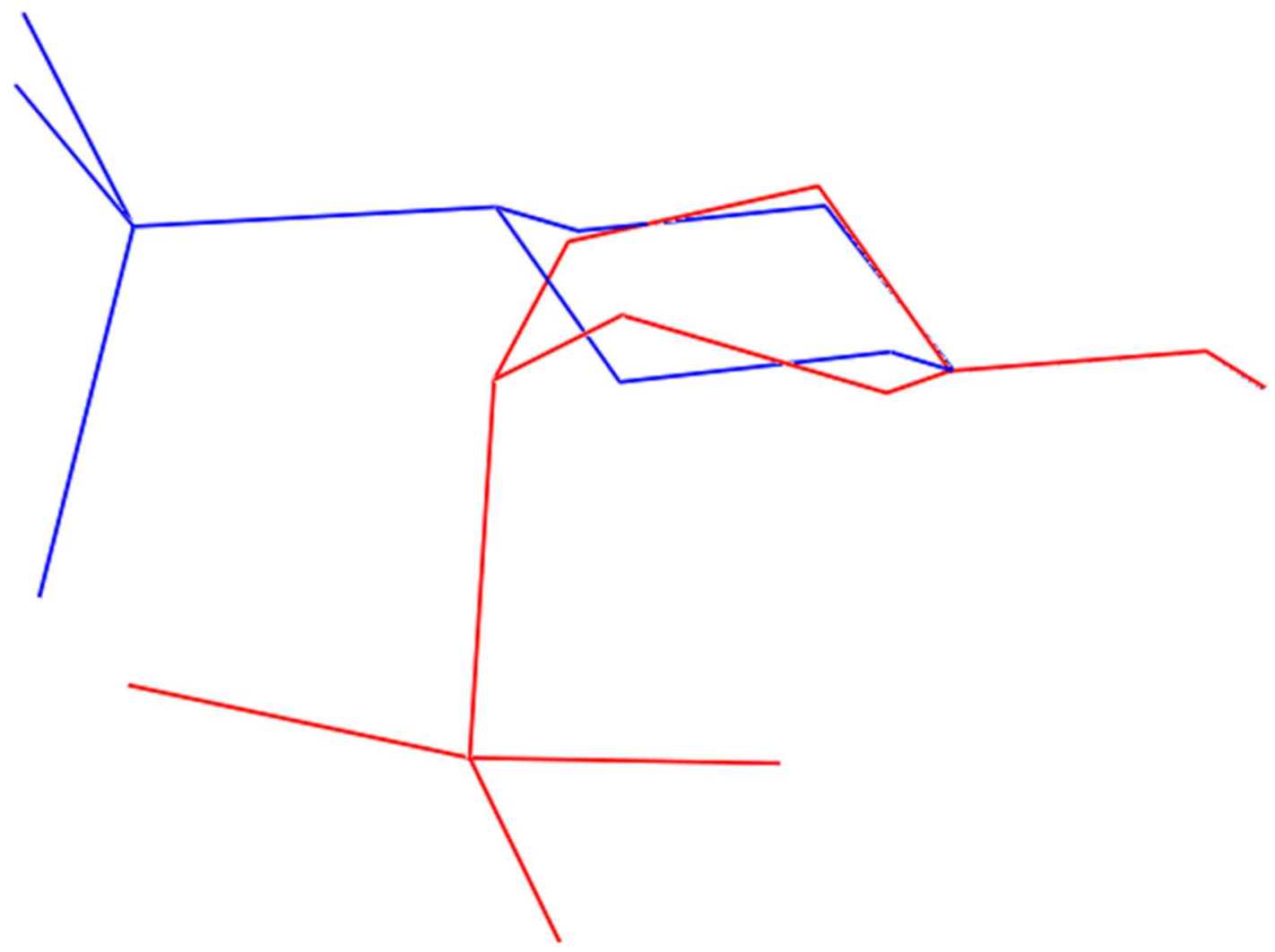

Fig. 7 Optimized geometry for the B3LYP/LanL2DZ (in red) compared to the geometry obtained by XRD (in blue). 

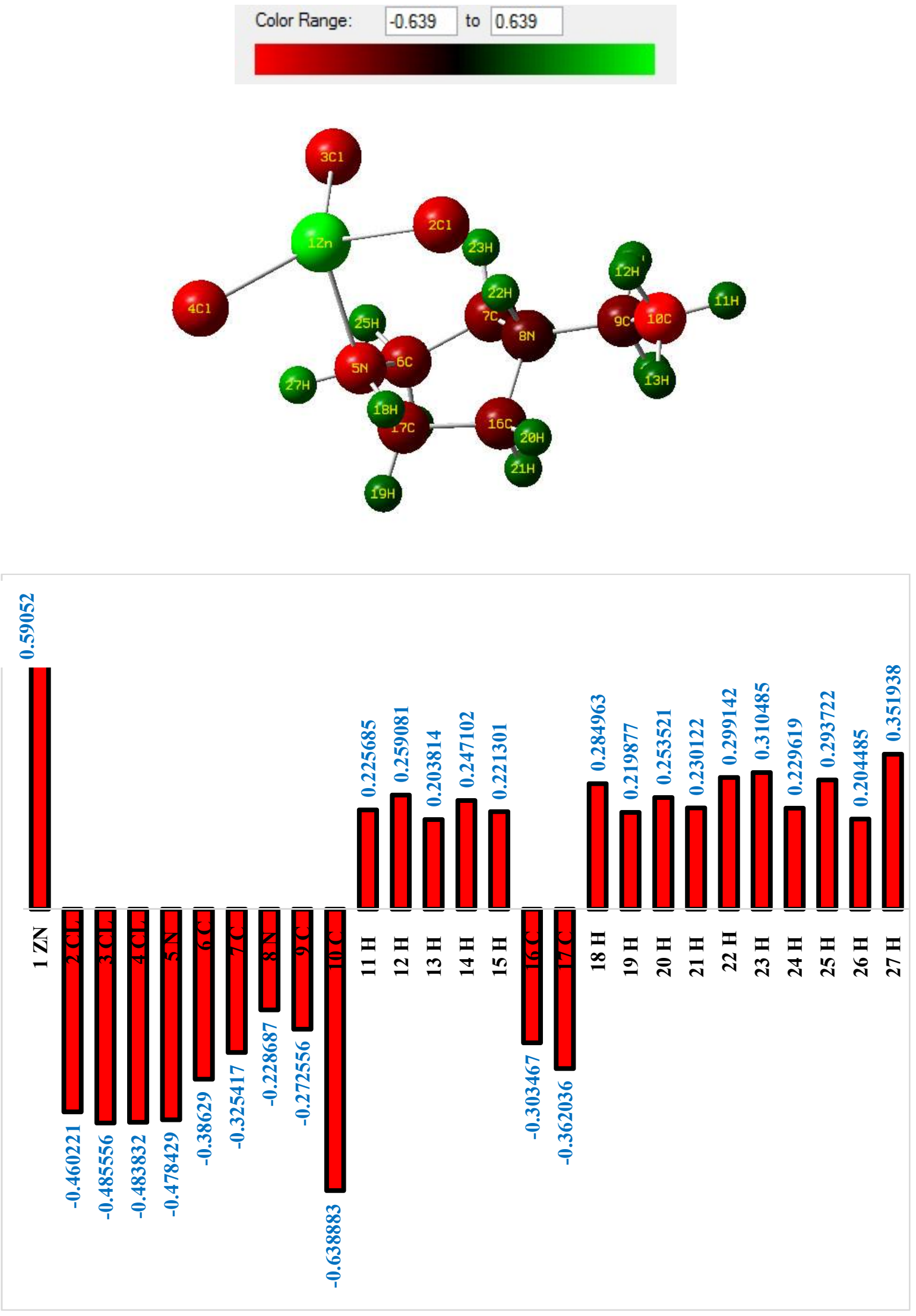

Fig. 8 Mulliken charge transfer in the title compound differentiated by color according to charge and Column chart of mulliken charges 


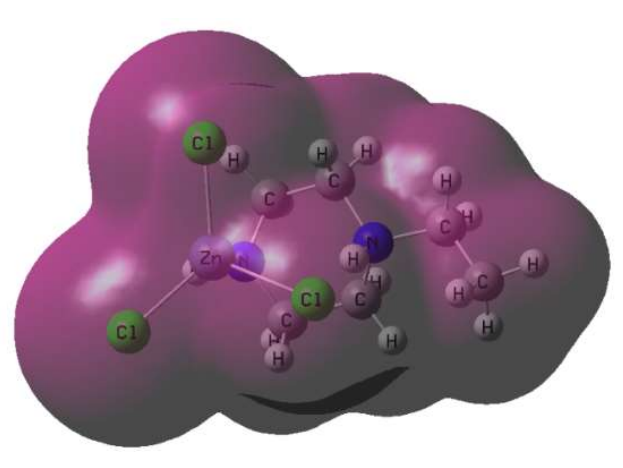

Total density

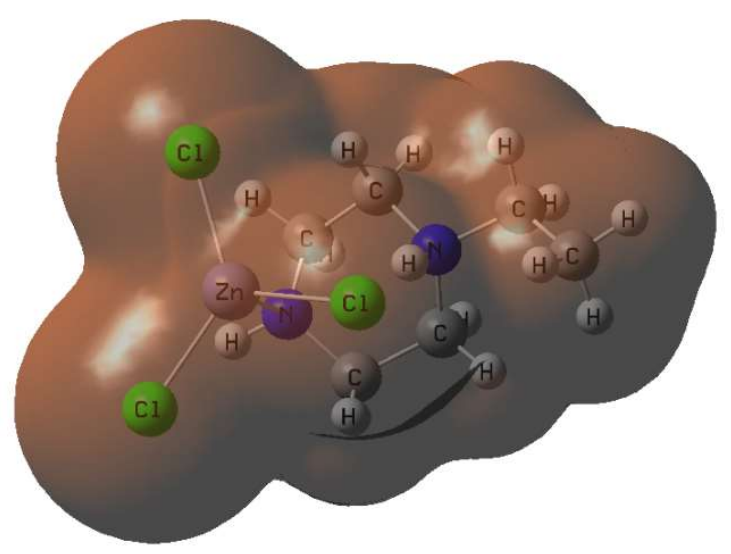

Alpha density

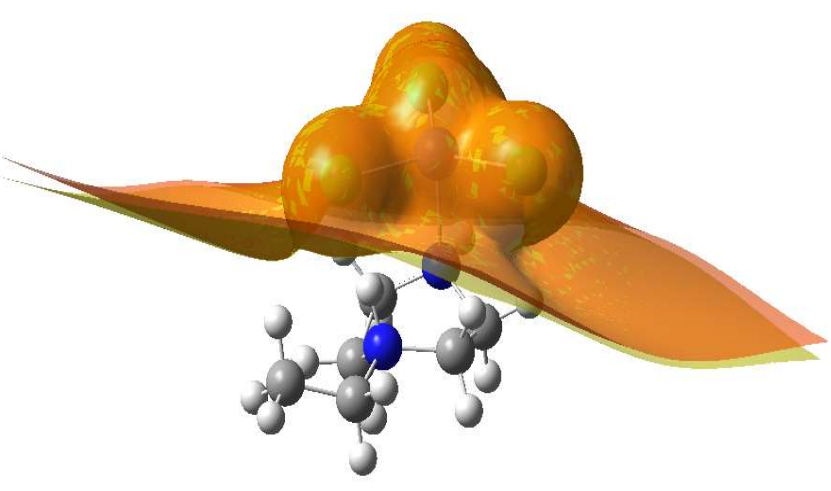

ESP

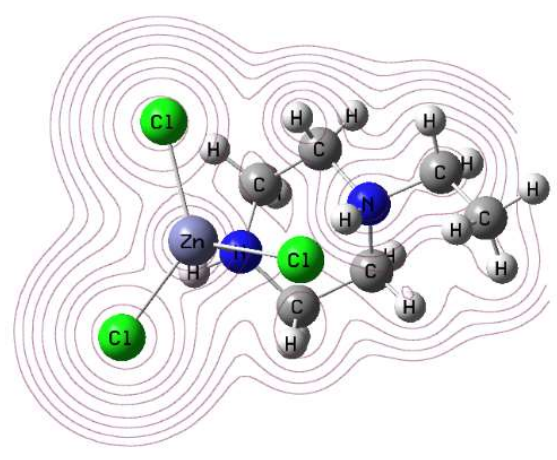

Contour (Total density)

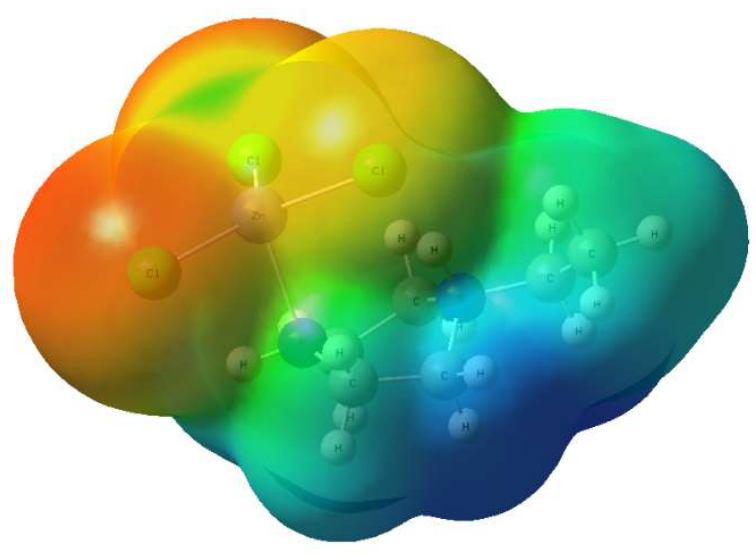

MEP

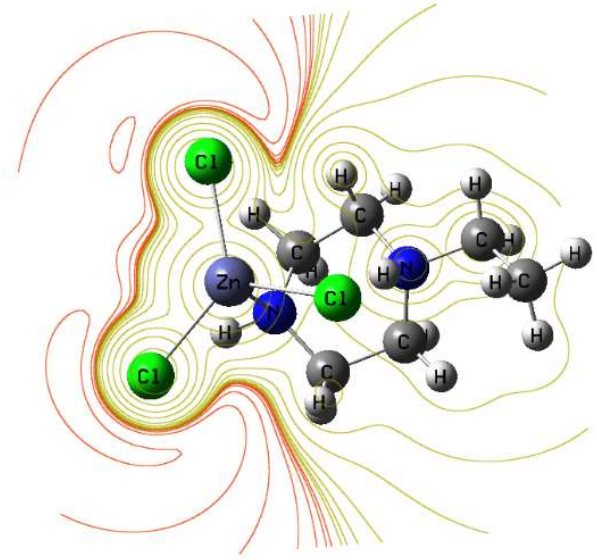

Contour (ESP)

Fig.9 Molecular surfaces of $\mathrm{C}_{6} \mathrm{H}_{15} \mathrm{~N}_{2} \mathrm{ZnCl}_{3}$. 


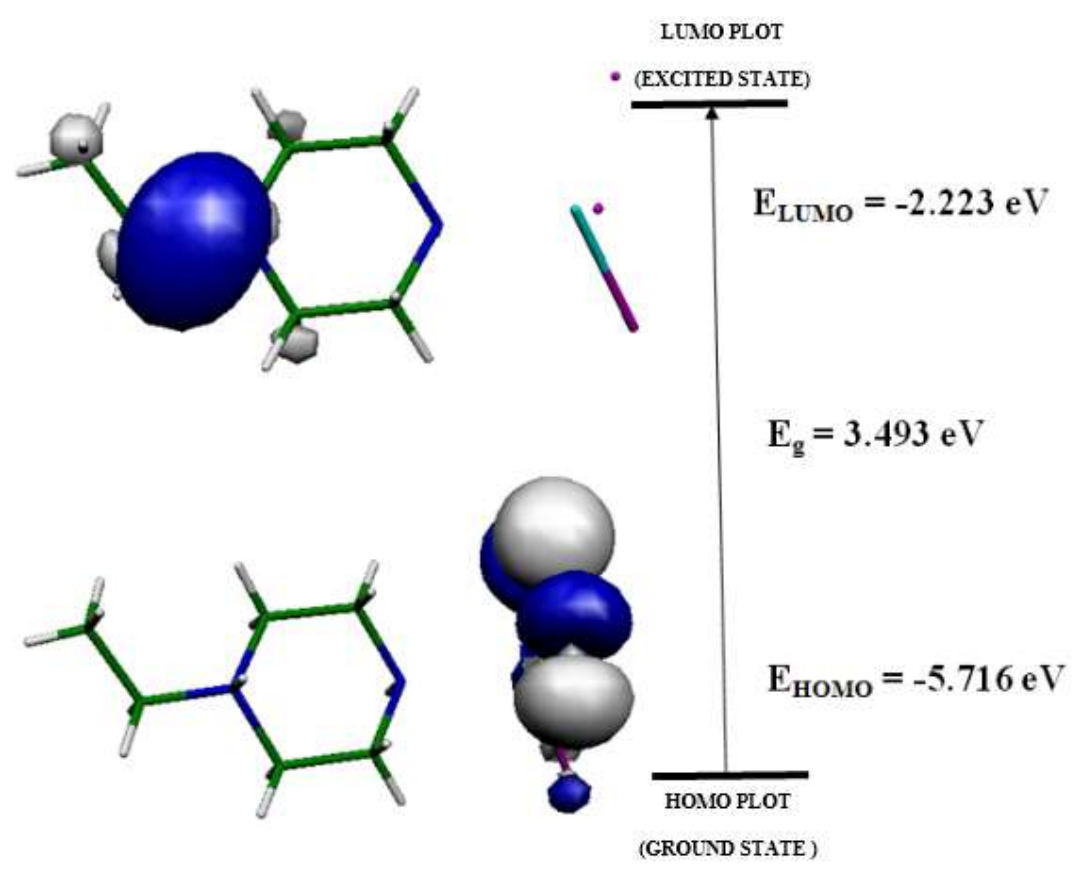

Fig. 10 Frontier molecular orbitals (HOMO and LUMO) of $\mathrm{C}_{6} \mathrm{H}_{15} \mathrm{~N}_{2} \mathrm{ZnCl}_{3}$.

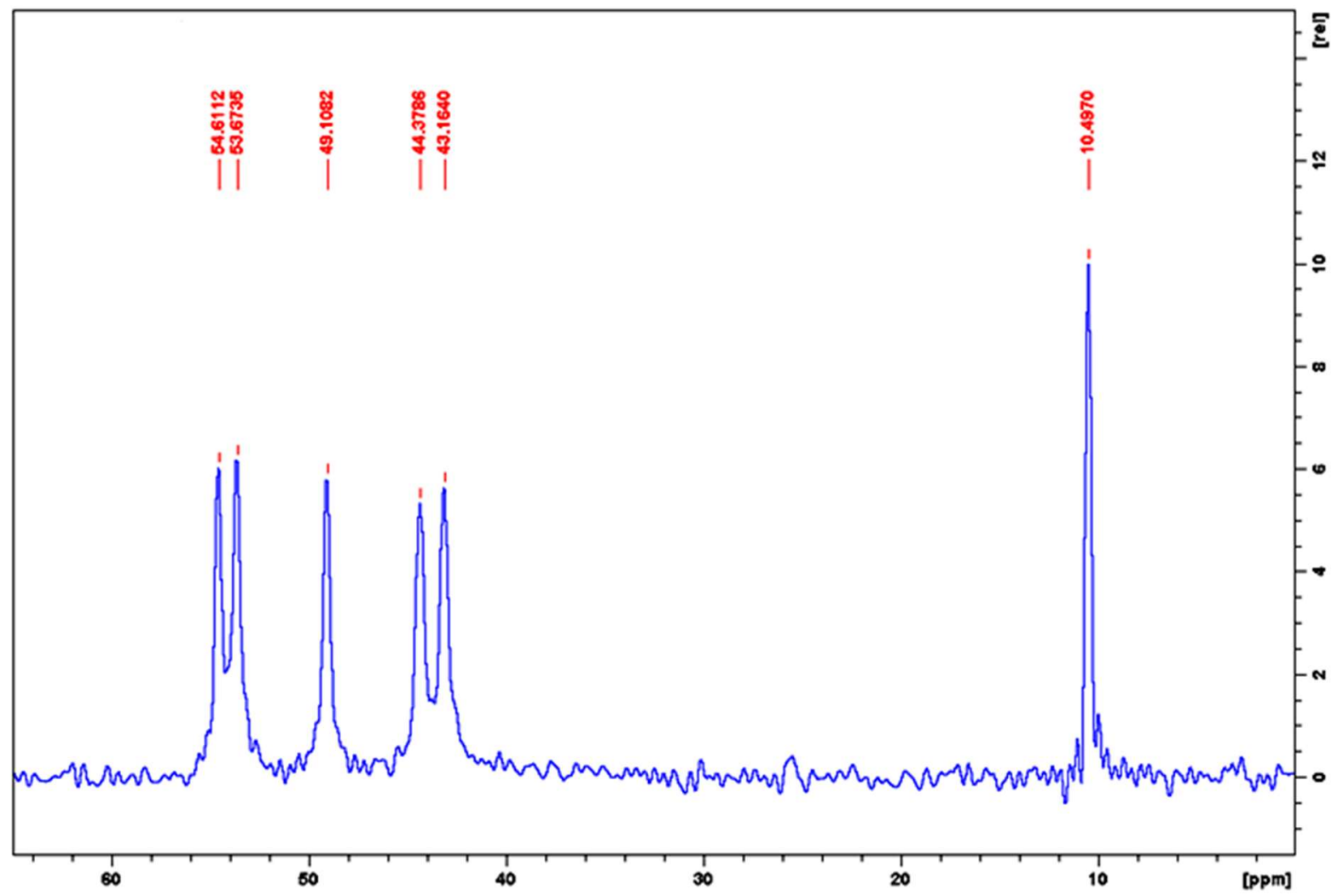

Fig. $11{ }^{13} \mathrm{C} \mathrm{CP-MAS} \mathrm{NMR} \mathrm{spectrum} \mathrm{of} \mathrm{C}_{6} \mathrm{H}_{15} \mathrm{~N}_{2} \mathrm{ZnCl}_{3}$. 


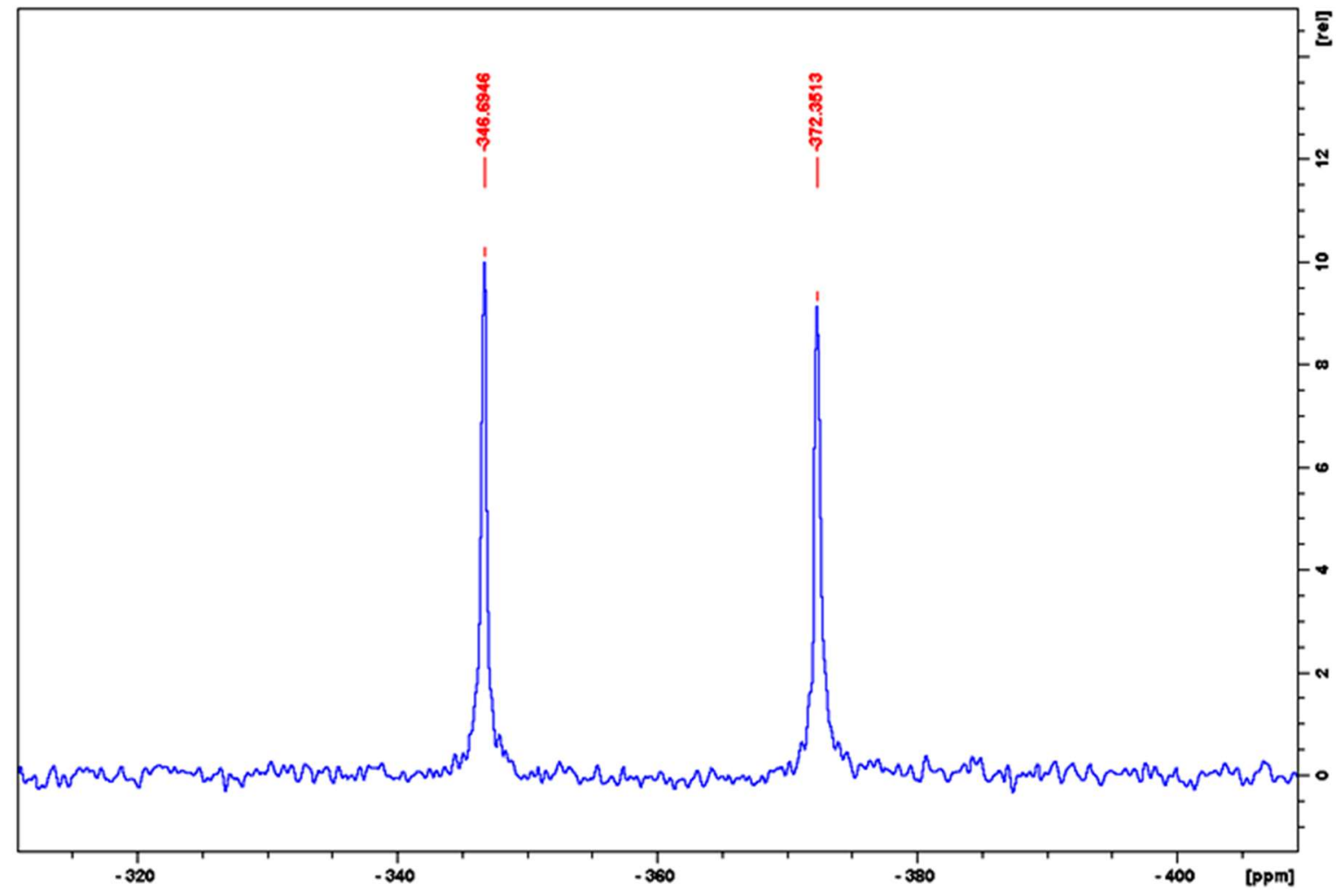

Fig. $12{ }^{15} \mathrm{~N} \mathrm{CP}-\mathrm{MAS}$ NMR spectrum of $\mathrm{C}_{6} \mathrm{H}_{15} \mathrm{~N}_{2} \mathrm{ZnCl}_{3}$

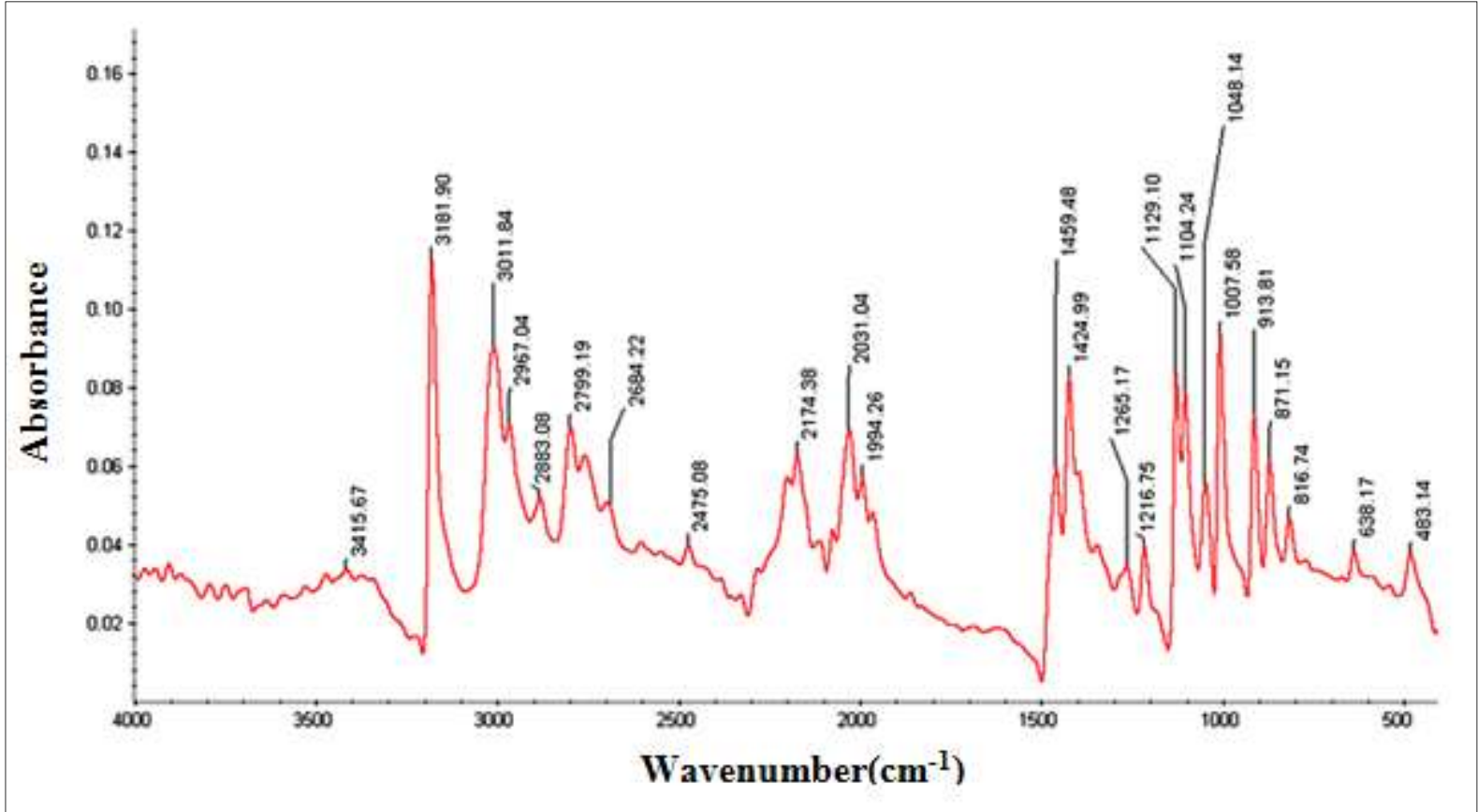

Fig. 13 Infrared absorption spectrum of $\mathrm{C}_{6} \mathrm{H}_{15} \mathrm{~N}_{2} \mathrm{ZnCl}_{3}$. 


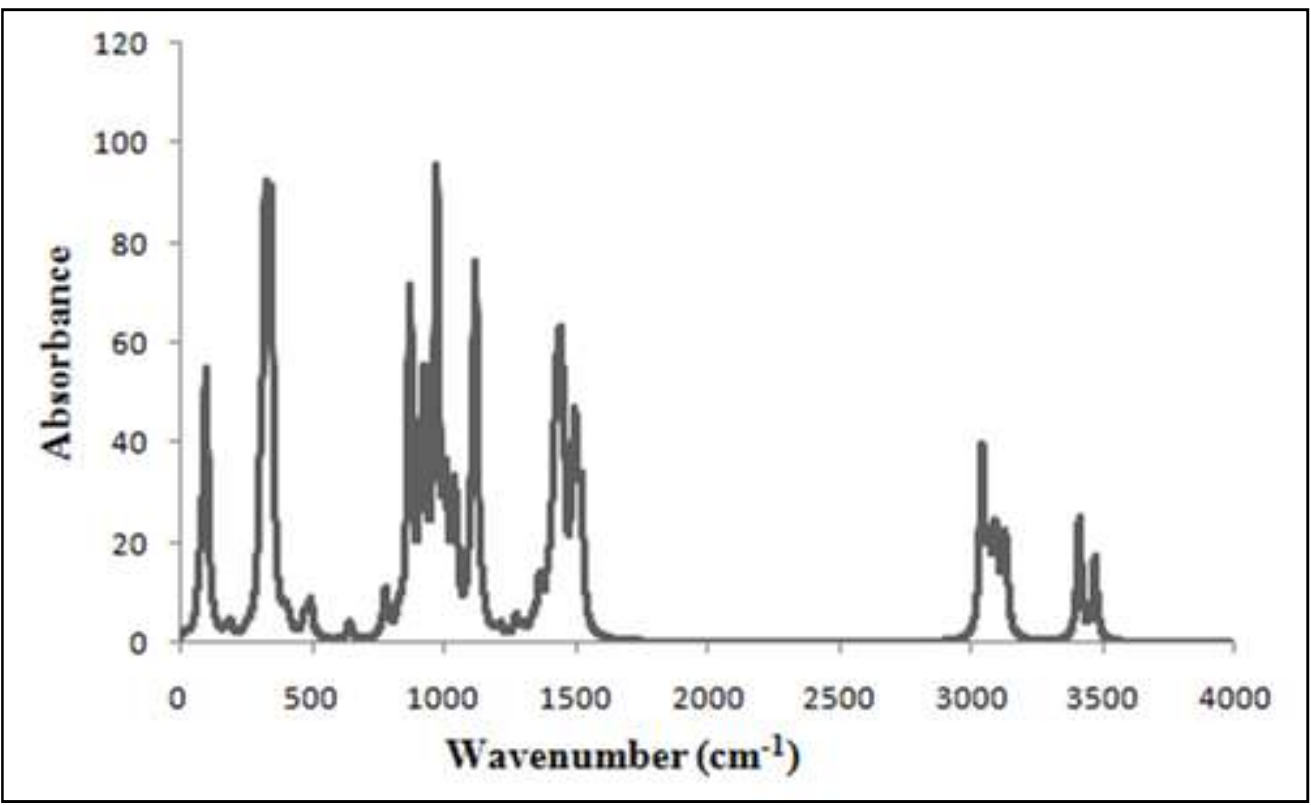

Fig. 14 Calculated IR absorption spectrum of $\mathrm{C}_{6} \mathrm{H}_{15} \mathrm{~N}_{2} \mathrm{ZnCl}_{3}$.

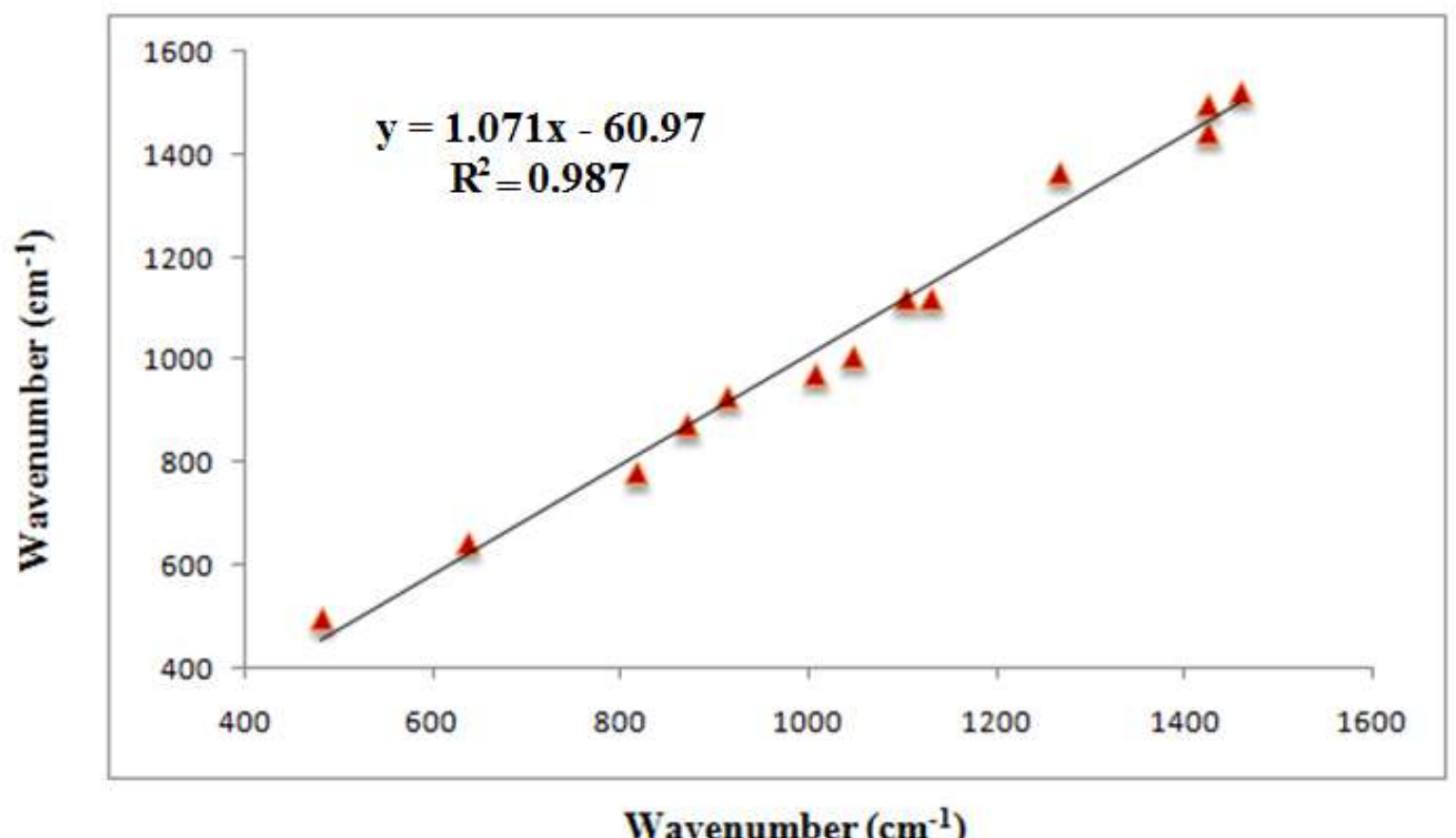

Fig. 15 Comparison between experimental and calculated frequencies of $\mathrm{C}_{6} \mathrm{H}_{15} \mathrm{~N}_{2} \mathrm{ZnCl}_{3}$. 
Table 1.Experimental details of $\mathrm{C}_{6} \mathrm{H}_{15} \mathrm{~N}_{2} \mathrm{ZnCl}_{3}$.

\section{Crystal data}

Chemical formula

$M_{\mathrm{r}}$

Crystal system, space group

Temperature $(\mathrm{K})$

$a, b, c(\AA)$

$\beta$

$V\left(\AA^{3}\right)$

Z

Radiation type

$\mu\left(\mathrm{mm}^{-1}\right)$

Crystal size (mm)

\section{$\mathrm{C}_{6} \mathrm{H}_{15} \mathrm{Cl}_{3} \mathrm{~N}_{2} \mathrm{Zn}$}

286.94

Monoclinic, $P 2{ }_{1} / n$

100

7.4490 (12) $\AA, 18.1170$ (4) $\AA, 8.4792$ (10)

$90.206(14)^{\circ}$

$1144.3(2)$

4

Mo $K \alpha$

2.80

$0.52 \times 0.36 \times 0.07$

No. of measured, independent and observed 9097, 2783, 2321

$[I>2 \sigma(I)]$ reflections

$R_{\text {int }}$

0.057

\section{Refinement}

$R\left[F^{2}>2 \sigma\left(F^{2}\right)\right], w R\left(F^{2}\right), S$

$0.053,0.154,0.98$

No. of reflections

2776

No. of parameters

115

$\Delta \rho_{\max }, \Delta \rho_{\min }\left(\mathrm{e} \AA^{-3}\right)$

$1.02,-1.33$ 
Table 2. Selected bond distances and angles $\left(\AA,{ }^{\circ}\right)$ and calculated geometric parameters of the title compound.

\begin{tabular}{|l|c|c|}
\hline Parameters & XRD Data & Theoretical data \\
\hline Bond lengths $(A)$ & & \\
\hline Zn1-C11 & $2.2532(11)$ & 2.429 \\
\hline Zn1-Cl2 & $2.2306(13)$ & 2.3273 \\
\hline Zn1-Cl3 & $2.2497(12)$ & 2.3151 \\
\hline Zn1-N1 & $2.067(4)$ & 2.2775 \\
\hline N1-C1 & $1.477(6)$ & 1.4885 \\
\hline N1-C2 & $1.479(6)$ & 1.4995 \\
\hline N2-C3 & $1.495(5)$ & 1.5166 \\
\hline C3-C2 & $1.511(6)$ & 1.5487 \\
\hline C5-C6 & $1.496(7)$ & 1.535 \\
\hline C4-N2 & $1.516(6)$ & 1.5339 \\
\hline N2-C5 & $1.504(5)$ & 1.5256 \\
\hline C1-C4 & $1.517(6)$ & 1.5433 \\
\hline Bond angles ( $)$ & & \\
\hline C11-Zn1-C12 & $114.67(5)$ & 111.1074 \\
\hline C11-Zn1-C13 & $109.25(4)$ & 118.2937 \\
\hline C12-Zn1-Cl3 & $115.01(5)$ & 128.3777 \\
\hline C11-Zn1-N1 & $107.58(11)$ & 97.8052 \\
\hline C12-Zn1-N1 & $102.91(11)$ & 98.7006 \\
\hline C13-Zn1-N1 & $106.67(11)$ & 88.9298 \\
\hline Zn1-N1-C1 & $113.7(3)$ & 115.5678 \\
\hline Zn1-N1-C2 & $111.8(3)$ & 114.1952 \\
\hline C1-N1-C2 & $109.7(3)$ & 112.4623 \\
\hline N1-C1-C4 & $112.2(4)$ & 108.5996 \\
\hline N2-C5-C6 & $112.5(4)$ & 113.2107 \\
\hline N2-C3-C2 & $111.0(4)$ & 110.2831 \\
\hline C1-C4-N2 & $109.6(3)$ & 111.3566 \\
\hline C3-C2-N1 & $112.5(4)$ & 110.3097 \\
\hline C4-N2-C5 & $110.1(3)$ & 110.7763 \\
\hline C4-N2-C3 & $110.2(3)$ & 110.8706 \\
\hline C5-N2-C3 & $113.5(4)$ & 114.057 \\
\hline
\end{tabular}


Table 3. Hydrogen-bond geometry $\left(A,{ }^{\circ}\right)$

\begin{tabular}{|l|l|l|l|l|}
\hline $\mathrm{D}-\mathrm{H} \cdots \mathrm{A}$ & $\mathrm{D}-\mathrm{H}$ & $\mathrm{H} \cdots \mathrm{A}$ & $\mathrm{D} \cdots \mathrm{A}$ & $\mathrm{D}-\mathrm{H} \cdots \mathrm{A}$ \\
\hline $\mathrm{C} 6-\mathrm{H} 6 \mathrm{C} \cdots \mathrm{Cl} 2^{\mathrm{i}}$ & 0.96 & 2.79 & $3.693(3)$ & $158(1)$ \\
\hline $\mathrm{N} 2-\mathrm{H} 2 \mathrm{~N} \cdots \mathrm{Cl} 1^{\mathrm{ii}}$ & $0.89(1)$ & $2.30(1)$ & $3.157(3)$ & $161(1)$ \\
\hline $\mathrm{C} 2-\mathrm{H} 2 \mathrm{~A} \cdots \mathrm{Cl} 2^{\mathrm{iii}}$ & 0.97 & 2.65 & $3.396(3)$ & $134(1)$ \\
\hline $\mathrm{N} 1-\mathrm{H} 1 \mathrm{~N} \cdots \mathrm{Cl} 3^{\text {iv }}$ & $0.89(1)$ & $2.39(1)$ & $3.273(3)$ & $173(1)$ \\
\hline
\end{tabular}

Symmetry codes: (i) $\mathrm{x}+1, y, z-1$; (ii) $x+1 / 2,-y+3 / 2, z^{-1 / 2}$; (iii) $x+1, y, z$; (iv) $-x+1,-y+1,-z+1$.

Table 4. Chemical proportions on the Hirshfeld surface, major interaction types and enrichment ratios.

\begin{tabular}{|c|c|c|c|c|c|c|}
\hline Enrichment & $\mathrm{Cl}$ & $\mathrm{Hn}$ & $\mathrm{C}$ & $\mathrm{N}$ & $\mathrm{Hc}$ & $\mathrm{Zn}$ \\
\hline $\mathrm{Cl}$ & 0.26 & & & & & \\
\hline $\mathrm{Hn}$ & 2.5 & 0 & & & & \\
\hline $\mathrm{C}$ & 0.99 & 0 & 0 & & & \\
\hline $\mathrm{N}$ & 0.02 & 0 & 0 & 0 & & \\
\hline $\mathrm{Hc}$ & 1.6 & 0 & 0.71 & 0 & 0.63 & \\
\hline $\mathrm{Zn}$ & 0.03 & 2.0 & 3.5 & 13.0 & 1.1 & 0.15 \\
\hline Surface $\%$ & 35.2 & 5.2 & 3.8 & 1.9 & 46.2 & 7.6 \\
\hline \% Main & $\mathrm{Hc} \ldots \mathrm{Cl}$ & Нc....Нc & $\mathrm{Hn} . . . \mathrm{Cl}$ & $\mathrm{Cl} \ldots \mathrm{Cl}$ & $\mathrm{Cl} \ldots \mathrm{C}$ & Hc...C \\
\hline Contacts & 53.4 & 13.5 & 9.1 & 3.3 & 2.7 & 2.6 \\
\hline
\end{tabular}


Table 5. The calculated thermodynamic parameters and total static dipole moment $(\mu)$ of $\mathrm{C}_{6} \mathrm{H}_{15} \mathrm{~N}_{2} \mathrm{ZnCl}_{3}$ determined by B3LYP/LanL2DZ.

\begin{tabular}{|l|l|}
\hline Thermodynamic Parameters & Values \\
\hline Thermal total energy $(\mathrm{kcal} / \mathrm{mol})$ & 151.231 \\
\hline Vibrational energy $(\mathrm{kcal} / \mathrm{mol})$ & 149.453 \\
\hline Zero point vibrational energy $(\mathrm{kcal} / \mathrm{mol})$ & 141.30908 \\
\hline Entropy $\left(\mathrm{Cal} / \mathrm{Mol}^{-1} \mathrm{k}^{-1}\right)$ Total & 129.642 \\
\hline Heat capacity $\left(\mathrm{Cal} / \mathrm{Mol}^{-1} \mathrm{k}^{-1}\right)$ & 53.777 \\
\hline Rotational constants $(\mathbf{G H z})$ & \\
\hline a & 0.66570 \\
\hline $\mathrm{b}$ & 0.34043 \\
\hline $\mathrm{c}$ & 0.33018 \\
\hline Dipole moment (Debye) & \\
\hline$\mu_{\mathrm{x}}$ & -16.0717 \\
\hline$\mu_{\mathrm{y}}$ & \\
\hline$\mu_{z}$ & \\
\hline$\mu_{\text {total }}$ & \\
\hline
\end{tabular}


Table 6. The calculated HOMO, LUMO energy values, HOMO-LUMO energy gap, electrophilicity index, electronegativity, chemical hardness and softness of the title compound.

\begin{tabular}{|l|l|}
\hline Parameters & 1 -ethylpiperaziniumtrichlorozincate (II) \\
\hline HOMO $(\mathrm{eV})$ & -5.716 \\
\hline LUMO $(\mathrm{eV})$ & -2.223 \\
\hline$|\Delta \mathrm{E}|($ energy gap $(\mathrm{eV}))$ & 3.493 \\
\hline$\chi(\mathrm{eV})$ & 3.9695 \\
\hline$\eta(\mathrm{eV})$ & 1.7465 \\
\hline$\xi(\mathrm{eV})$ & 0.286 \\
\hline$\psi(\mathrm{eV})$ & $15.756 / 3.493=4.511$ \\
\hline
\end{tabular}

Table 7. Comparison of calculated and experimental chemical shift values of the carbon and nitrogen atoms in title compound.

\begin{tabular}{|c|c|c|c|c|}
\hline Atoms & X-Rays & $\begin{array}{c}\text { Optimisation of } \\
\text { protons }\end{array}$ & $\begin{array}{c}\text { Optimisation of } \\
\text { all atoms }\end{array}$ & Experimental \\
\hline C1 & -13.1 & 11.2 & 11.2 & 10.5 \\
\hline C2 & 40.2 & 58.3 & 58.1 & 54.6 \\
\hline C3 & 46.3 & 65.4 & 52.0 & 49.1 \\
\hline C4 & 38.6 & 57.2 & 53.7 & 53.7 \\
\hline C5 & 31.5 & 47.1 & 42.7 & 44.4 \\
\hline C6 & 30.2 & 46.8 & 41.4 & 43.2 \\
\hline N1 & -336.9 & -305.6 & -315.1 & -372.4 \\
\hline N2 & -313.2 & -276.9 & -294.2 & -346.7 \\
\hline
\end{tabular}

